\title{
OBSERVATIONS OF CHANGES IN ACOUSTIC EMISSION WAVEFORM FOR VARYING SEEDED DEFECT SIZES IN A ROLLING ELEMENT BEARING
}

\author{
Saad Al-Dossary ${ }^{1}$, R.I. Raja $\operatorname{Hamzah}^{2}$, D. $\mathrm{Mba}^{2}$ \\ ${ }^{1}$ Consulting services, Saudi Aramco, Dhahran, Saudi Arabia \\ ${ }^{2}$ School of Mechanical Engineering, Cranfield University, Cranfield, Beds. MK43 OAL. \\ d.mba@ cranfield.ac.uk, Fax: +44 (0) 1234754681
}

\begin{abstract}
The investigation reported in this paper was centered on the application of the Acoustic Emissions (AE) technology for characterising the defect sizes on a radially loaded bearing. An experimental test-rig was designed such that defects of varying sizes could be seeded onto the outer and inner races of a test bearing. The aim of this investigation was to correlate defect size with specific AE parameters and to ascertain the relationship between the duration of $\mathrm{AE}$ transient bursts associated with seeded defects to the actual geometric size of the defect. In addition, the use of AE to detect inner race defects was explored particularly as this known to be fraught with difficulty. It is concluded that the geometric defect size of outer race defects can be determined from the AE waveform.
\end{abstract}

Keywords: Acoustic emissions, bearing defect size, bearing fault diagnosis, condition monitoring.

\section{Introduction}

Acoustic emissions (AE) are defined as the range of phenomena that results in structure-borne propagating waves being generated by the rapid release of energy from localised sources within and/or, on the surface of a material. In this particular 
investigation, AE's are defined as the transient elastic waves generated by the interaction of two surfaces in relative motion. The interaction of surface asperities and impingement of the bearing rollers over a seeded defect will generate AE's. Due to the high frequency content of the AE signatures typical mechanical noise (less than 20 $\mathrm{kHz}$ ) is eliminated. A comprehensive review of the application of the AE technology for bearing monitoring was presented by Mba et al [1] where it was shown that the AE technology offered earlier fault identification than vibration analysis, particularly for outer race defects; this was not mirrored for inner race defect identification.

Shiroishi et al [2] noted difficulties in identifying inner race defects with AE stating that emissions from inner race defects were not of sufficient strength/energy to be detectable above the operational background noise. Shiroishi postulated reasons for this stating that AE signals generated by an inner race defect had to travel further and through more interfaces than those for any other type of defect (e.g., the outer race). Also, it was commented that the signal strength may diminish if the transmission path for the $\mathrm{AE}$ wave was not direct to the sensor; implying that the transmission path will be influenced by the position of the defect, the roller, and the sensor. This observation was also recently presented by Tan [3] et al where the viability of the AE technology for gear defect detection by making observations from non-rotating components (bearing casings) of a machine was called into question. Several other authors have shown the advantages of applying AE to monitoring of rolling element bearings [4 17].

The aim of this paper is to ascertain the applicability of AE for detecting the presence of inner and outer race defects, particularly as the former has been reported to be 
fraught with difficulty. Furthermore, the paper builds on the investigation of AlGhamdi [18, 19] by exploring further the relationship between time-domain AE waveform characteristics with seeded defect geometric dimensions of the inner and outer race.

\section{Experimental apparatus and data acquisition}

The test bearing was fitted on a rig which consisted of a shaft that was driven by a motor. The shaft was supported by two large slave bearings, see figure 1 . The test bearing was a split Cooper cylindrical roller type 01B40MEX, with a bore diameter of $40 \mathrm{~mm}$, external diameter of $84 \mathrm{~mm}$, pitch circle diameter of $68 \mathrm{~mm}$, roller diameter of $12 \mathrm{~mm}$, and 10 rollers in total. This bearing was selected due to its split design which would facilitate the assembling and disassembling of the bearing on the shaft after each test.

The AE acquisition system consisted of a piezoelectric type sensor (Physical Acoustic Corporation type WD) fitted onto the top half of the bearing housing. The transducer had an operating frequency of 100 to $1000 \mathrm{kHz}$. The signal from the transducer was amplified at $40 \mathrm{~dB}$ and sampled at $8 \mathrm{MHz}$ for outer race experiments, and, $4 \mathrm{MHz}$ and $8 \mathrm{MHz}$ for the inner race experiments at $1500 \mathrm{rpm}$ and $3000 \mathrm{rpm}$ respectively. 


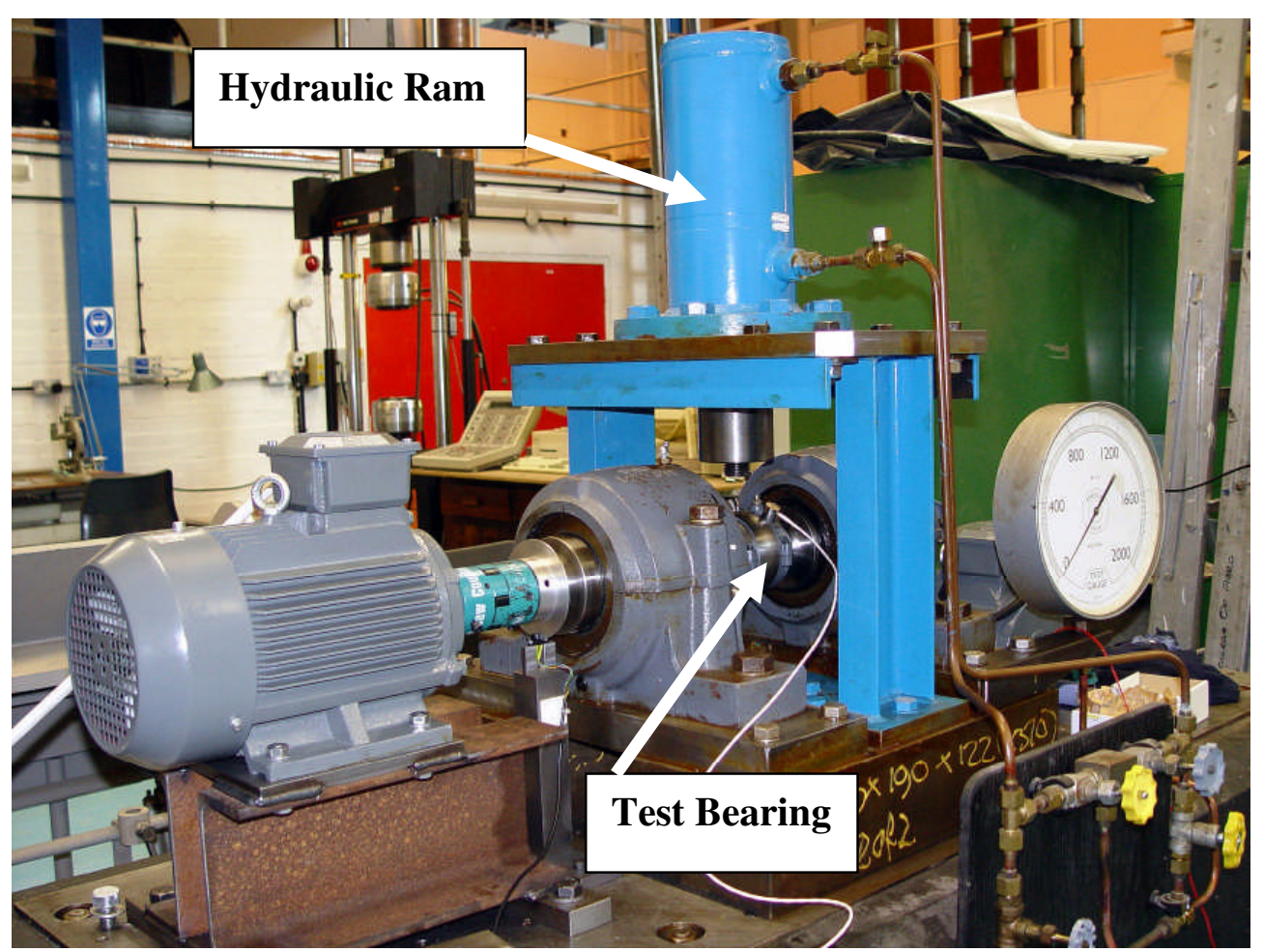

Figure $1 \quad$ Layout of experimental test-rig

Experimental Procedure

Four split Cooper bearings were used for the experiment in order to seed a variety of defects on each bearing. The defects on the bearing elements were made by using an electric engraver with a carbide tip. In an attempt to understand how the defect size influenced AE waveform an incremental procedure for simulating increasing defect sizes was established. This involved starting a sequence on a bearing with a point defect (D1) and increasing the length along the circumferential direction to a maximum value for a fixed width across the race. Once this maximum length was achieved the width of the defect was then expanded. A breakdown on the incremental 
defect procedure is detailed in tables 1(a) to 1(d). In all tests the smallest defect seeded had a diameter of $0.5 \mathrm{~mm}$ which was labelled 'D1'. The defect sizes were measured by its Length $(\mathrm{mm})$ and Width $(\mathrm{mm})$, where the length was measured circumferentially in the direction of the rollers and the width is defined as the distance across the bearing race.

Table ( 1a ) Bearing-1 incremental defect sizes (outer race)

\begin{tabular}{|c|c|}
\hline \multicolumn{2}{|c|}{ Bearing $1(L X W) \mathrm{mm}$} \\
\hline$D 1$ & Circle $D=0.5 \mathrm{~mm}$ \\
\hline D2 & $0.9 \times 2.5 \mathrm{~mm}$ \\
\hline D3 & $0.9 \times 4$ \\
\hline$D 4$ & $0.9 \times 8$ \\
\hline D5 & $0.9 \times 12$ \\
\hline D6 & $3 \times 12$ \\
\hline D7 & $5 \times 12$ \\
\hline$D 8$ & $7 x 12$ \\
\hline D9 & $9 \times 12$ \\
\hline
\end{tabular}

Table ( 1c ) Bearing-3 incremental defect sizes (inner race)

\begin{tabular}{|l|c|}
\hline \multicolumn{2}{|l|}{ Bearing 3 $(\boldsymbol{L} \mathbf{W}) \mathbf{m m}$} \\
\hline D17 & Circle $D=0.5 \mathrm{~mm}$ \\
\hline D18 & $3 x 1$ \\
\hline D19 & $6 x 1$ \\
\hline D20 & $12 x 1$ \\
\hline D21 & $12 \times 3$ \\
\hline D22 & $12 x 6$ \\
\hline
\end{tabular}

Table ( 1b ) Bearing-2 incremental defect sizes (outer race)

\begin{tabular}{|c|c|}
\hline \multicolumn{2}{|c|}{ Bearing 2 $(L X W) \mathrm{mm}$} \\
\hline D10 & $1 \times 2$ \\
\hline D11 & $2 \times 2$ \\
\hline$D 12$ & $4 \times 2$ \\
\hline$D 13$ & $8 \times 2$ \\
\hline D14 & $12 \times 2$ \\
\hline$D 15$ & $12 \times 6$ \\
\hline D16 & $12 \times 9$ \\
\hline
\end{tabular}

Table ( 1d ) Bearing-4 incremental defect sizes (inner race)

\begin{tabular}{|c|c|}
\hline Bearing 4(L $\boldsymbol{X ~ W}) \mathbf{m m}$ \\
\hline D23 & $1 \times 3$ \\
\hline $\mathbf{D 2 4}$ & $1 \times 6$ \\
\hline D25 & $1 \times 12$ \\
\hline D26 & $3 \times 12$ \\
\hline D27 & $6 \times 12$ \\
\hline
\end{tabular}

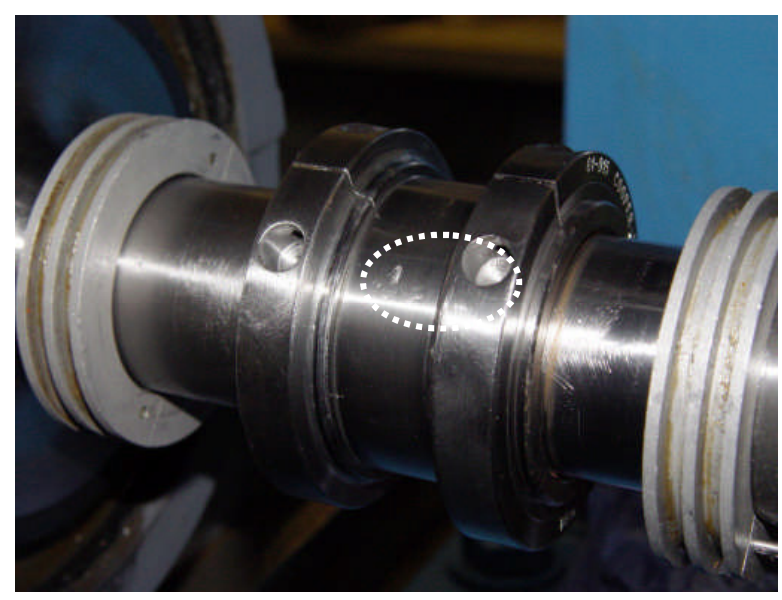




\section{Figure 2 A sample of an inner race defect}

Experimental tests were performed by first making the defects in the appropriate size and geometrical shape, see figure 2, on the bearing element after which the bearing was installed and positioned such that the defect was at the top-dead-centre where the load was applied. After installing the bearing, the test rig was run at the first speed of $1500 \mathrm{rpm}$ for at least fifteen minutes to bring it up to thermal equilibrium. Next, forces of $2.7,5.3$, and $8 \mathrm{kN}$ were applied in sequence and $\mathrm{AE}$ data was acquired for each load condition. The rig was shutdown and the motor changed to provide a speed of 3000rpm. The procedure for loading and AE data acquisition was repeated again. The bearing was then dismantled and the next incremental defect was seeded onto the bearing element. The test sequence described above was again undertaken. A total of 162 tests were performed for this investigation.

\section{Analysis}

For each test performed (162 in total), $42 \mathrm{AE}$ data files were acquired. The averaged energy and maximum amplitude values for all 42 data files associated with each defect condition are presented as a function of speed, load and defect size.

\subsection{Observations of Energy values for the outer race (Bearings 1 and 2)}

The energy values were compared for increasing outer race defect sizes at varying speed and load conditions. It was noted that energy values increased with increasing speed and load. For tests involving Bearing's -1 and -2 , incrementally increasing the 
defect size resulted in an increase in energy values at both speed conditions, see figures 3 and 4 .

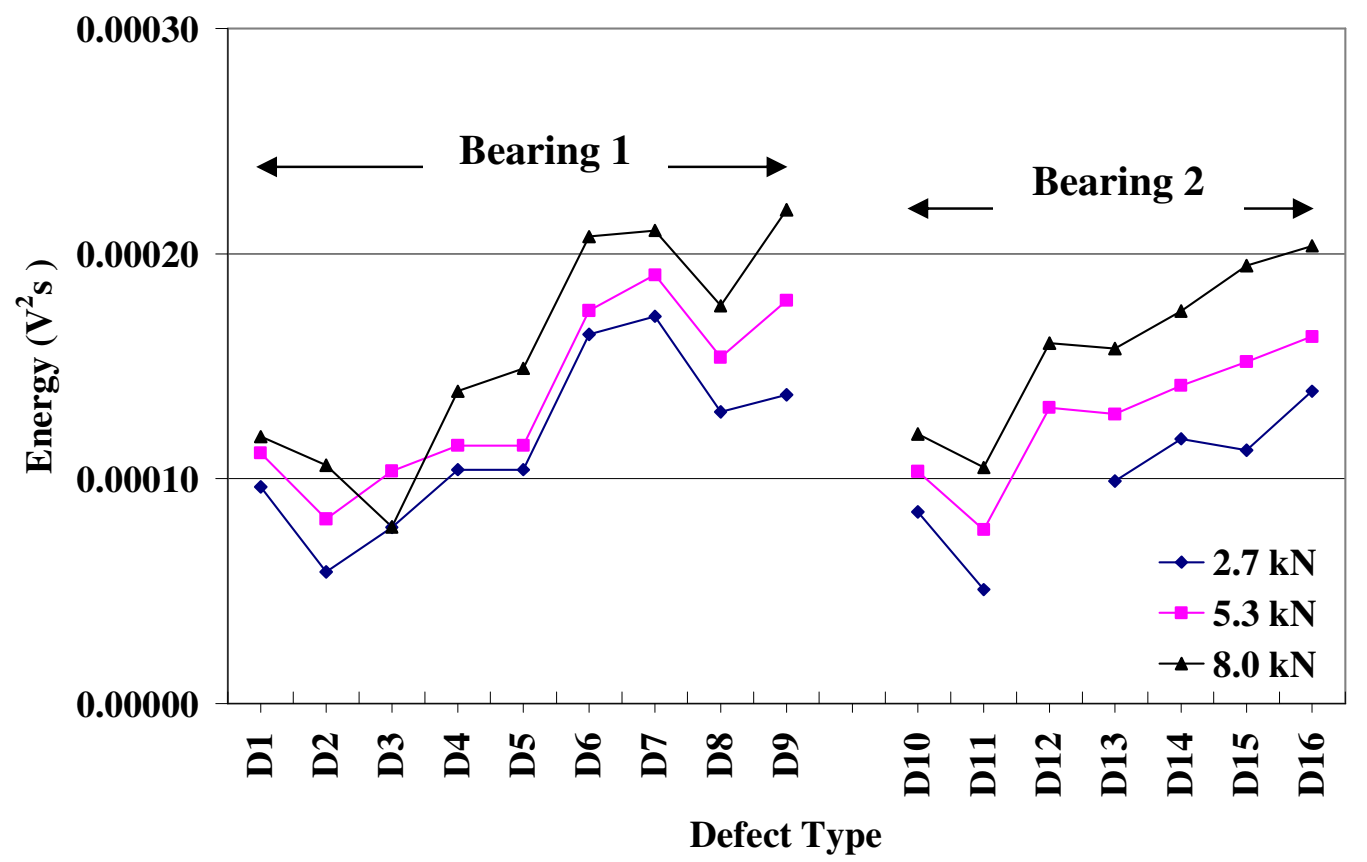

Figure 3 AE Energy for varying defect and load conditions; Outer race, 1500rpm

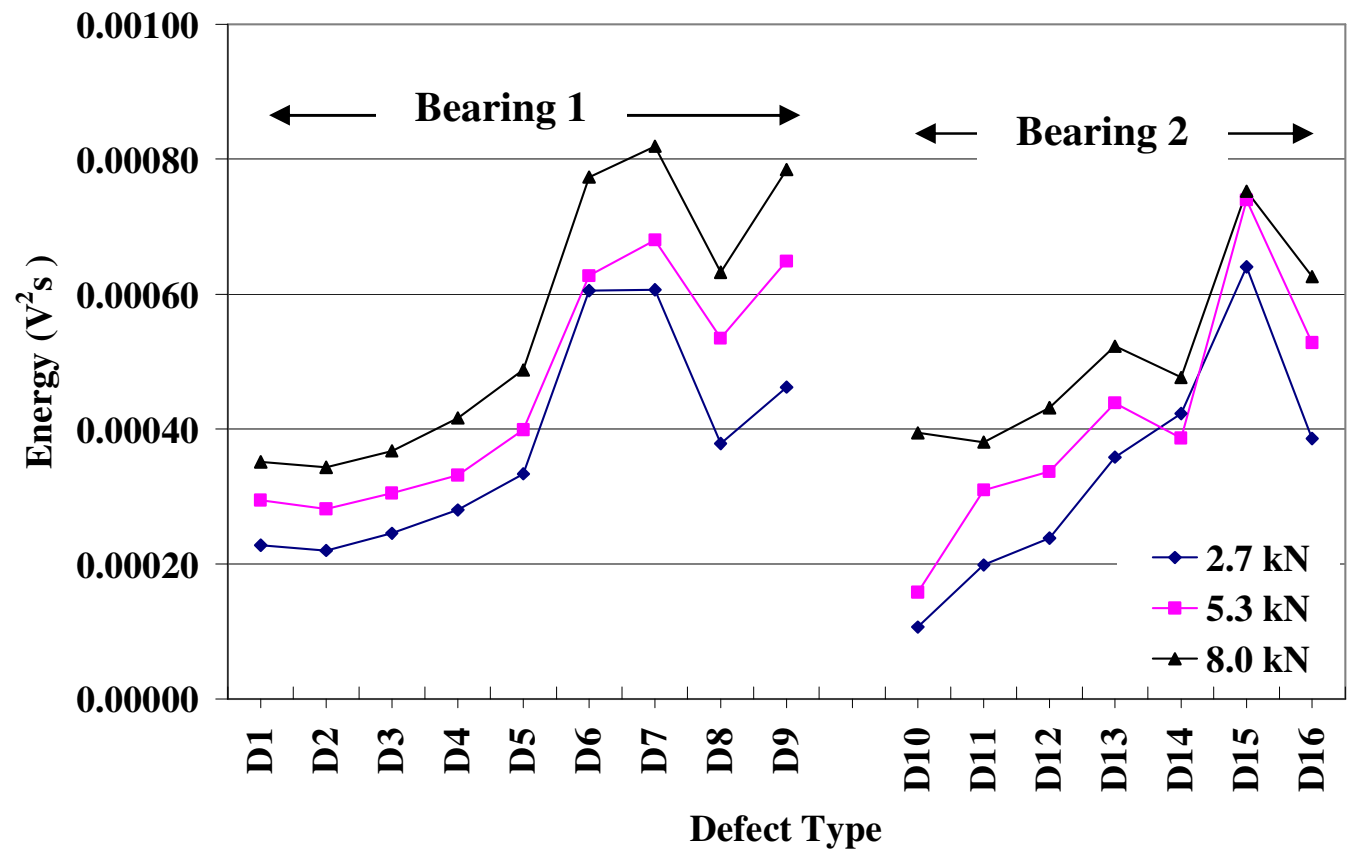




\section{Figure 4 AE Energy for varying defect and load conditions; Outer race, 3000rpm}

\subsection{Observations of Maximum Amplitude values for the Outer Race (Bearings 1 and 2)}

As with the energy values, the maximum amplitude values showed a general increase with defect size at both rotational speeds (1500 and 3000rpm). However, it was noted that maximum amplitude values presented in figures 5 and 6 reached a maximum and then decreased, for instance, observations of bearing- 1 in figure 6 showed amplitude values increased from D1 to D5. By further increasing the width of defect size incrementally (D6 to D9), it was noted that maximum amplitude values decreased. This trend was also noted for bearing-1, where the procedure of increasing defect sizes was reverse to Bearing-2; indicating that this observation was independent of the direction in which the defect grew and rotational speed. 


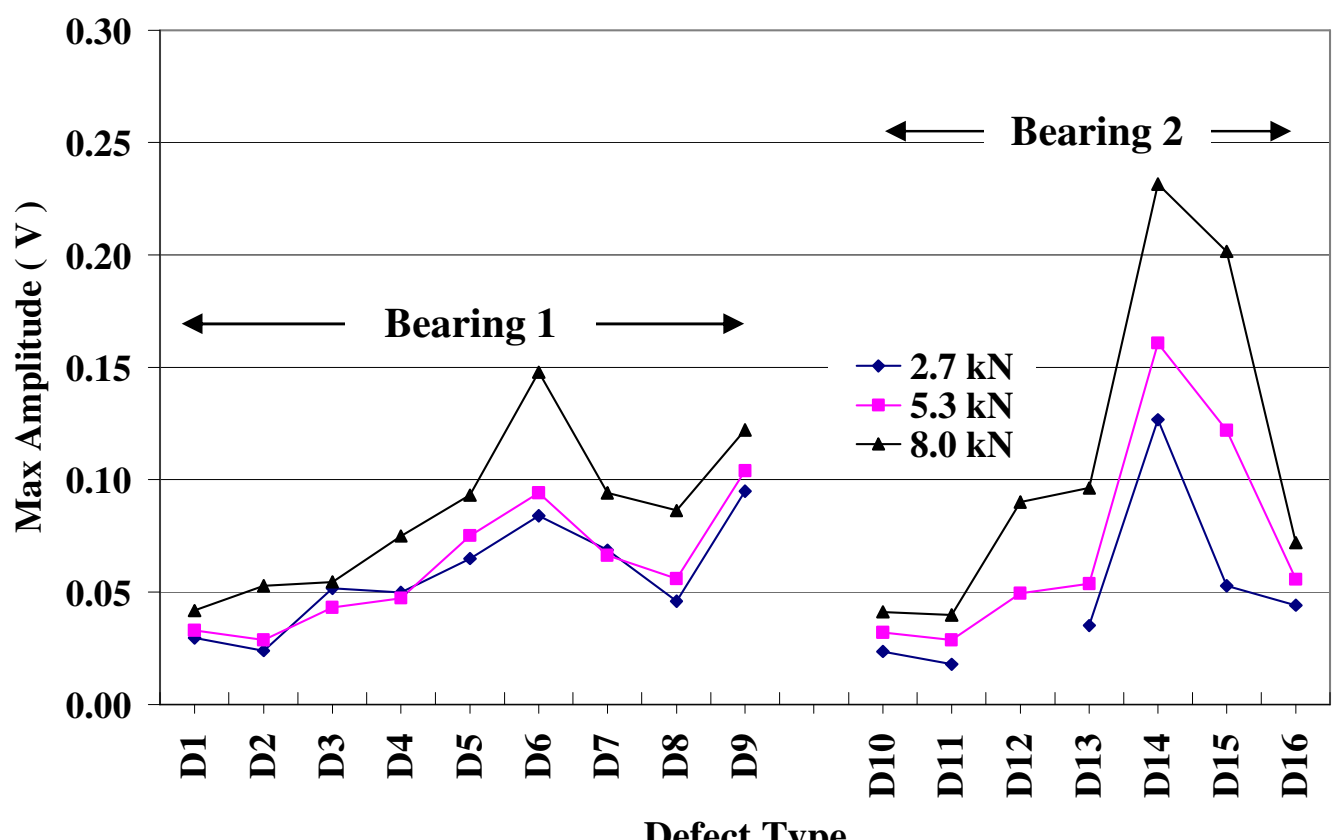

Figure 5 AE maximum amplitude for varying defect and load conditions; outer race, $1500 \mathrm{rpm}$

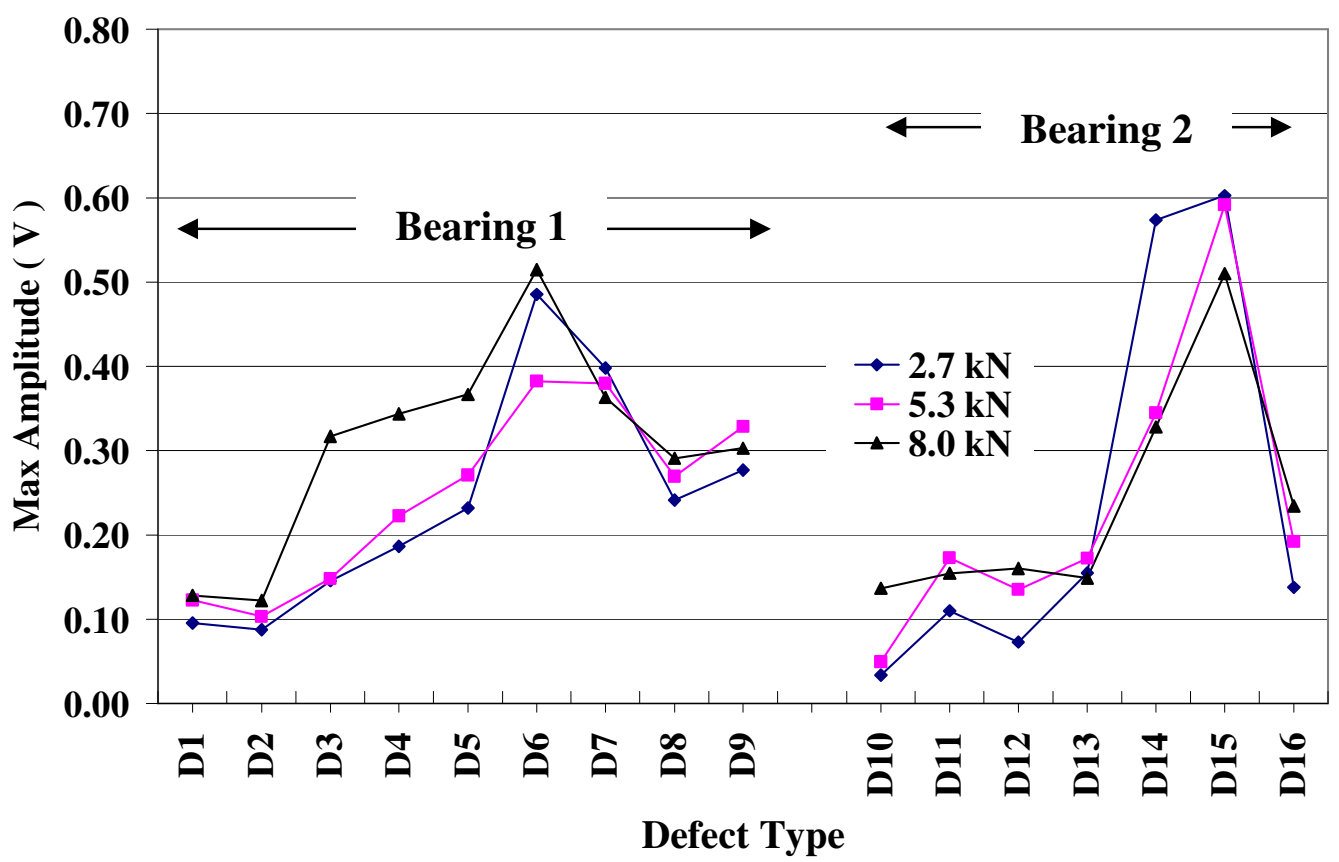

Figure 6 AE maximum amplitude for varying defect and load conditions; outer race, $3000 \mathrm{rpm}$ 
4.3 Observations of Energy values for Inner race defects (Bearings 3 and 4)

The AE energy values measured for inner race defects showed a general trend of increasing energy values with increasing defect size, see figures 7 and 8 .

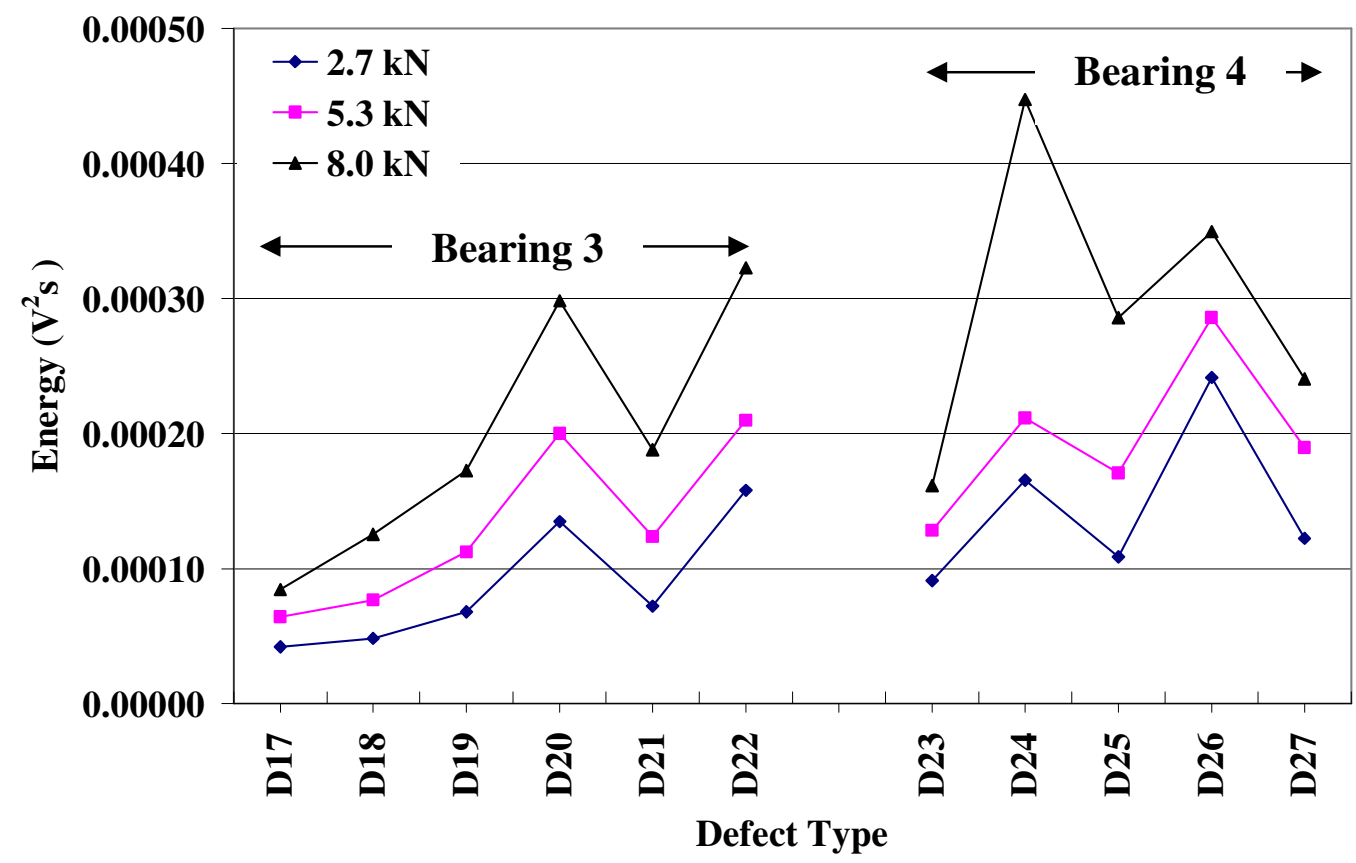

Figure 7 AE Energy for varying defect and load conditions; inner race, 1500rpm 


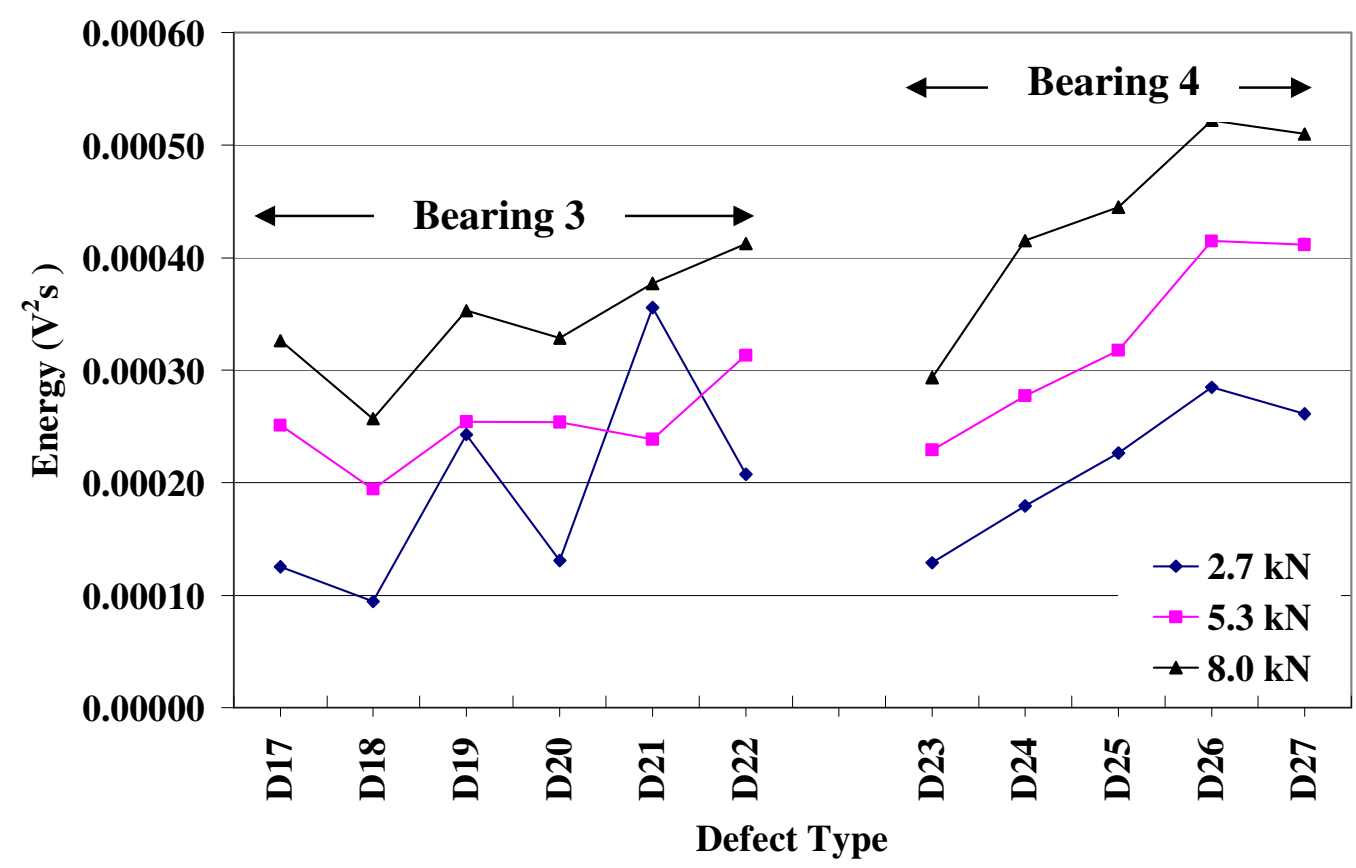

Figure 8 AE Energy for varying defect and load conditions; Inner race, 3000rpm

\subsection{Observations of maximum amplitude values for the inner race experiment}

(Bearings 3 and 4)

The AE maximum amplitude values associated with inner race seeded defects showed random characteristics. The AE maximum amplitude values did not show any pattern when they were plotted against the defect size for both Bearing-3 and -4 under two speed conditions, see figures 9 and 10. The values showed a random increase and decrease as the defect size increased in length or width. 


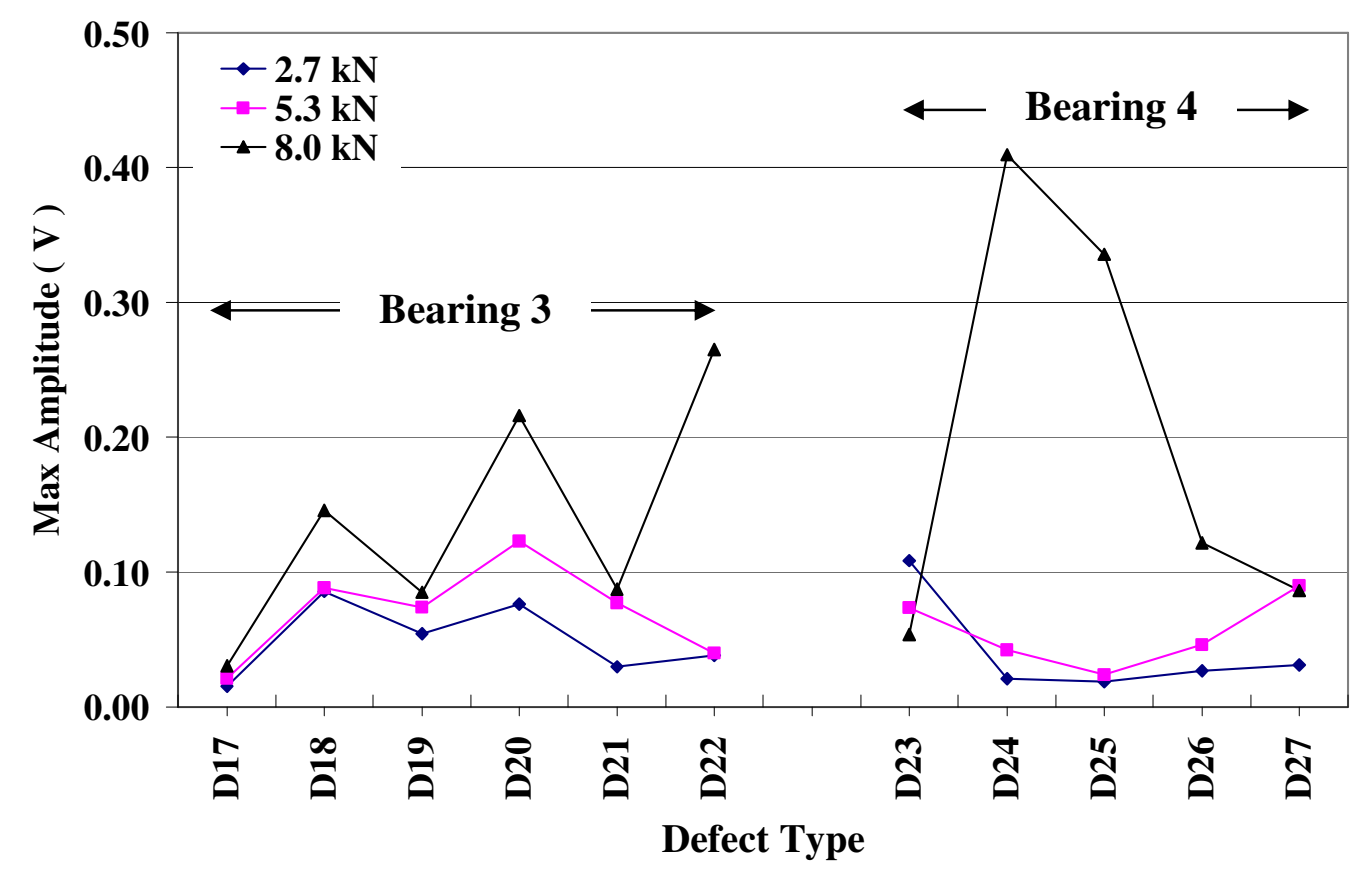

Figure 9 AE maximum amplitude for varying defect and load conditions; inner race, 1500rpm

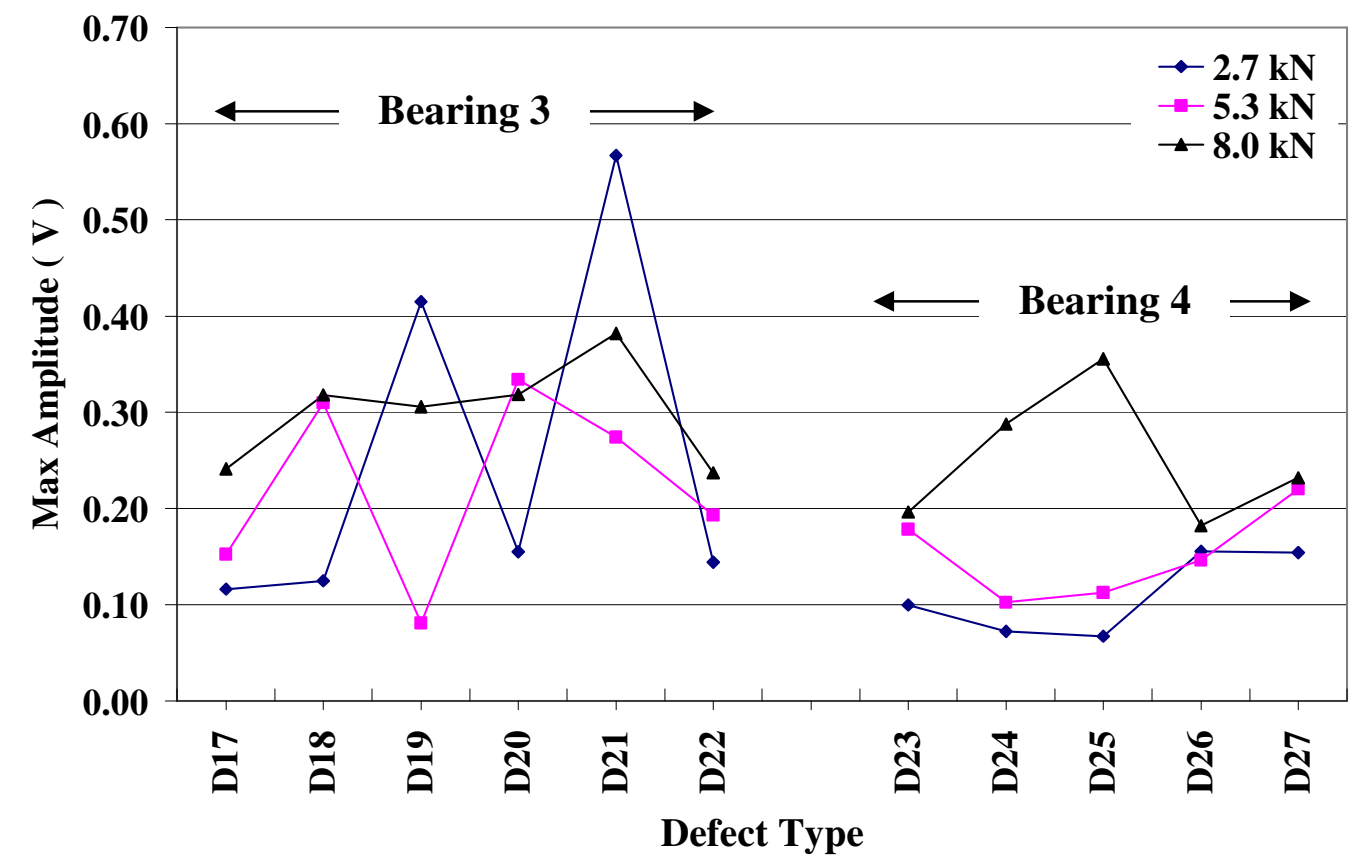

Figure 10 AE maximum amplitude for varying defect and load conditions; inner race, 3000rpm 


\subsection{Observations of burst duration for Outer and Inner race defects}

This part of the experiment involved relating the duration of $\mathrm{AE}$ transient bursts with the size of defect. If the defects simulated were to produce $\mathrm{AE}$ transient bursts, as each rolling element passed the defect, it was envisaged that the AE bursts would be detected at a rate equivalent to the outer race and inner race defect frequencies (4.1times and 5.8-times rotational speed respectively). This periodicity in AE transient was noted for both the outer and inner race defects; see figure 11. At 3000rpm the number of revolutions captured over $32 \mathrm{msec}$ (time window for data acquisition, as shown in figure 11) was 1.6; implying that there should be approximately ' 6 ' and ' 9 ' $\mathrm{AE}$ transient bursts associated with the outer and inner race defect frequencies in figure 11. At the lower speed of $1500 \mathrm{rpm}$, the data acquisition time window allowed for 0.8 and 1.6 revolutions of the shaft for the outer and inner race defect simulations respectively; implying approximately '4' and '9' $\mathrm{AE}$ transient bursts for each acquisition window. Appendix A highlights sample AE waveforms for varying speed, load and defect conditions. However, whilst the anticipated number of anticipated AE transients bursts associated with outer race defects was consistently captured in the data acquisition time window (see top plot in figure 11) the same did not always apply for the inner race defects. In the latter instance there was a variation in the measured number of AE transients. This is discussed in greater detail under section 7. 

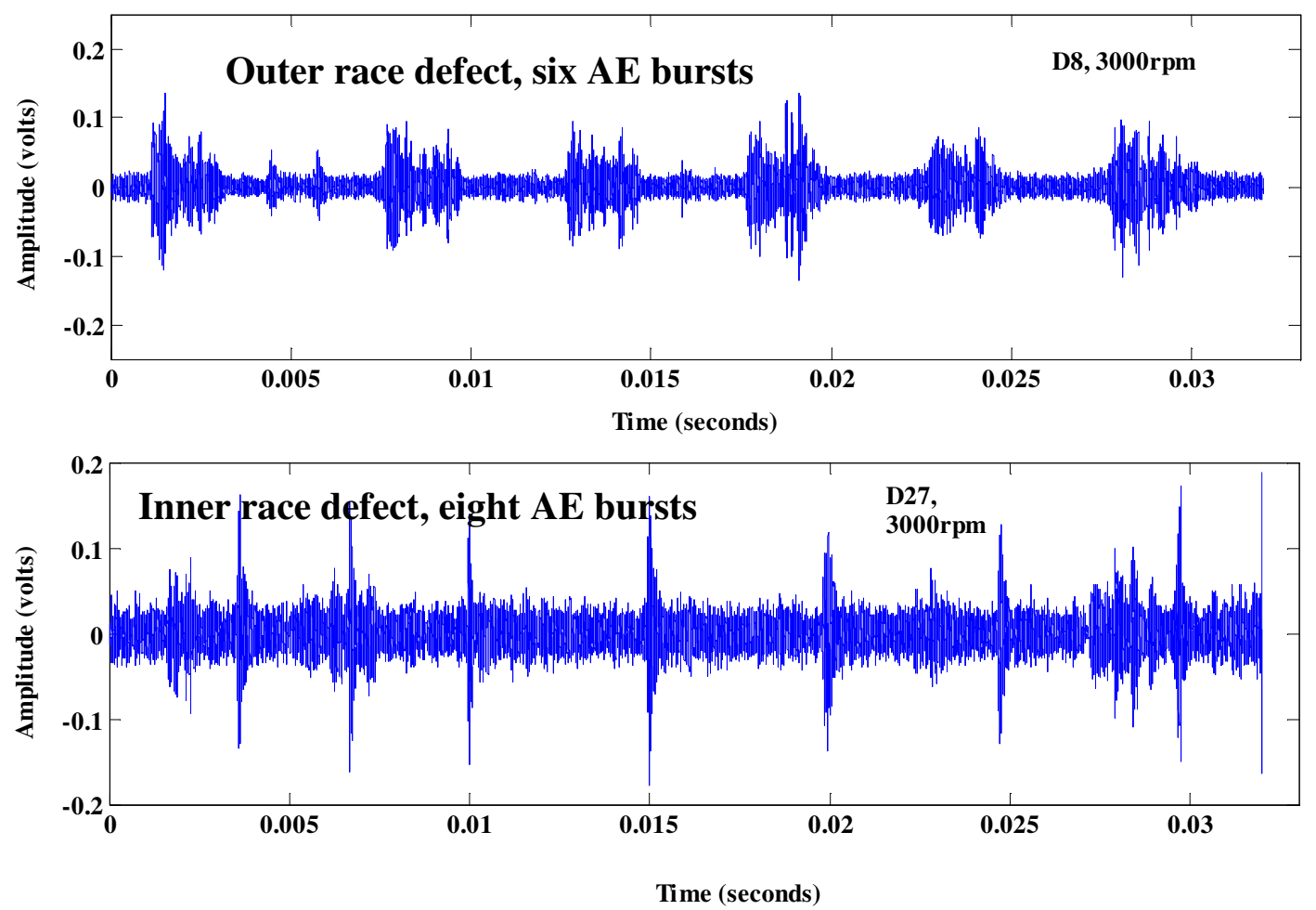

\section{Figure 11 AE transient bursts associated with outer and inner race defects (3000rpm)}

The AE transient burst duration associated with specific defects was obtained by calculating the duration from the point at which the AE response was higher than the underlying background noise level to the point at which it returned to the underlying noise level. This simply implied defining the start and end of each burst and determining the duration, as shown in figure 12. The duration value presented for each defect condition was an average value taken from over twenty AE bursts per defect size taken at random. A complete breakdown of average burst duration for bearings 1 and 3 at 1500 and 3000rpm, with AE waveform plots, is presented in appendix A. The waveform plots in appendix A present a good qualitative observation of the influence of changing defect size on $\mathrm{AE}$ waveform. 


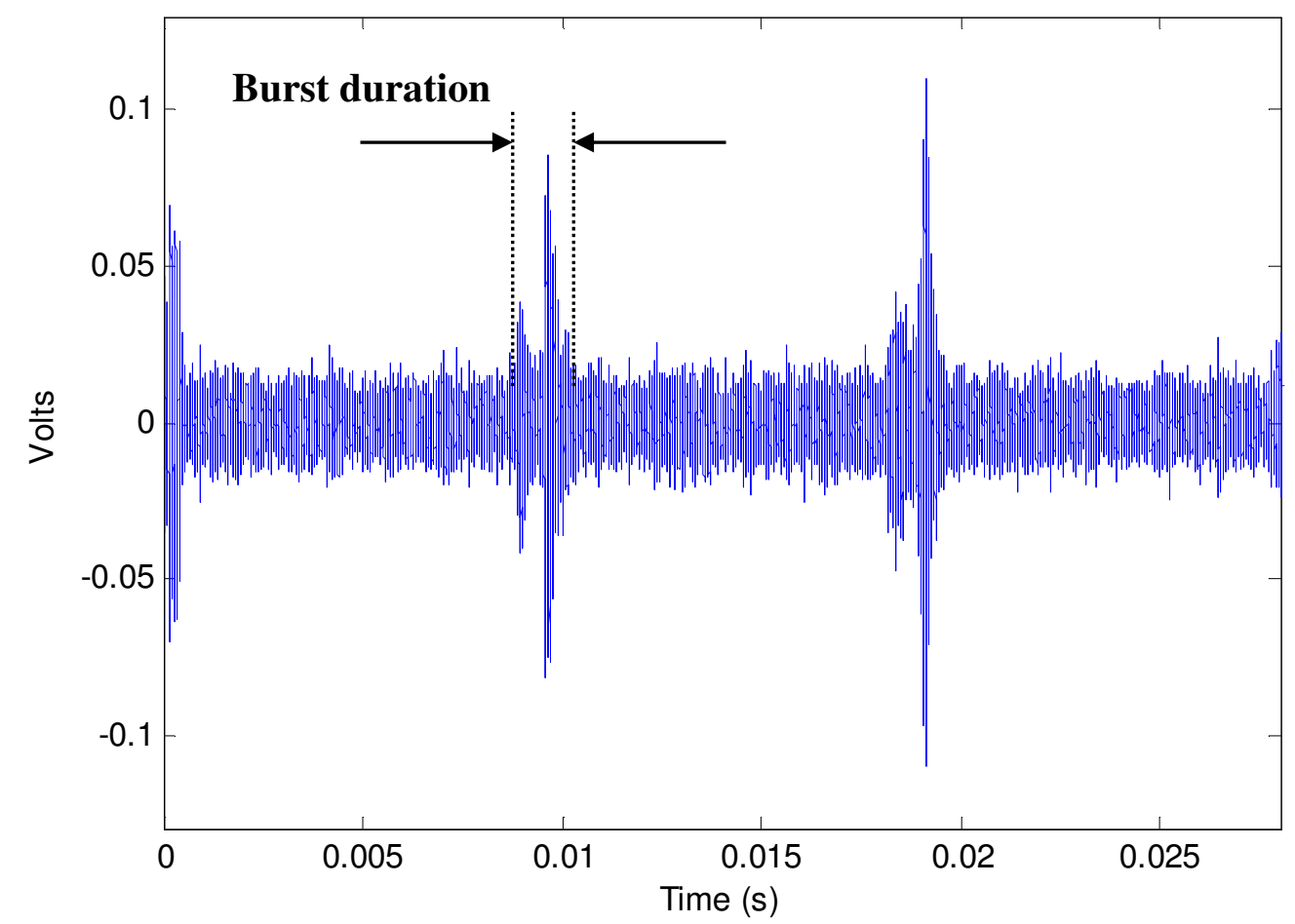

$\begin{array}{ll}\text { Figure } 12 & \text { Example procedures for determining the AE transient burst } \\ \text { duration }\end{array}$

It is important to note that defect D1 was a point defect, D2 to D5 had fixed length with increasing width and D6 to D9 had a fixed width with increasing length, as described in table 1(a). For bearings- 1 and -3 no AE transient bursts associated with defect D1 were evident above the operational background noise levels, see appendix A. For defects D2 to D5 the AE burst duration associated with the defect condition remained relatively constant irrespective of the speed and load condition (see figures 13 and 14), however, the duration of the AE burst associated with defects D6 to D9 increased with increasing defect size along the circumferential direction of the roller (length), see figures 13 and 14. 


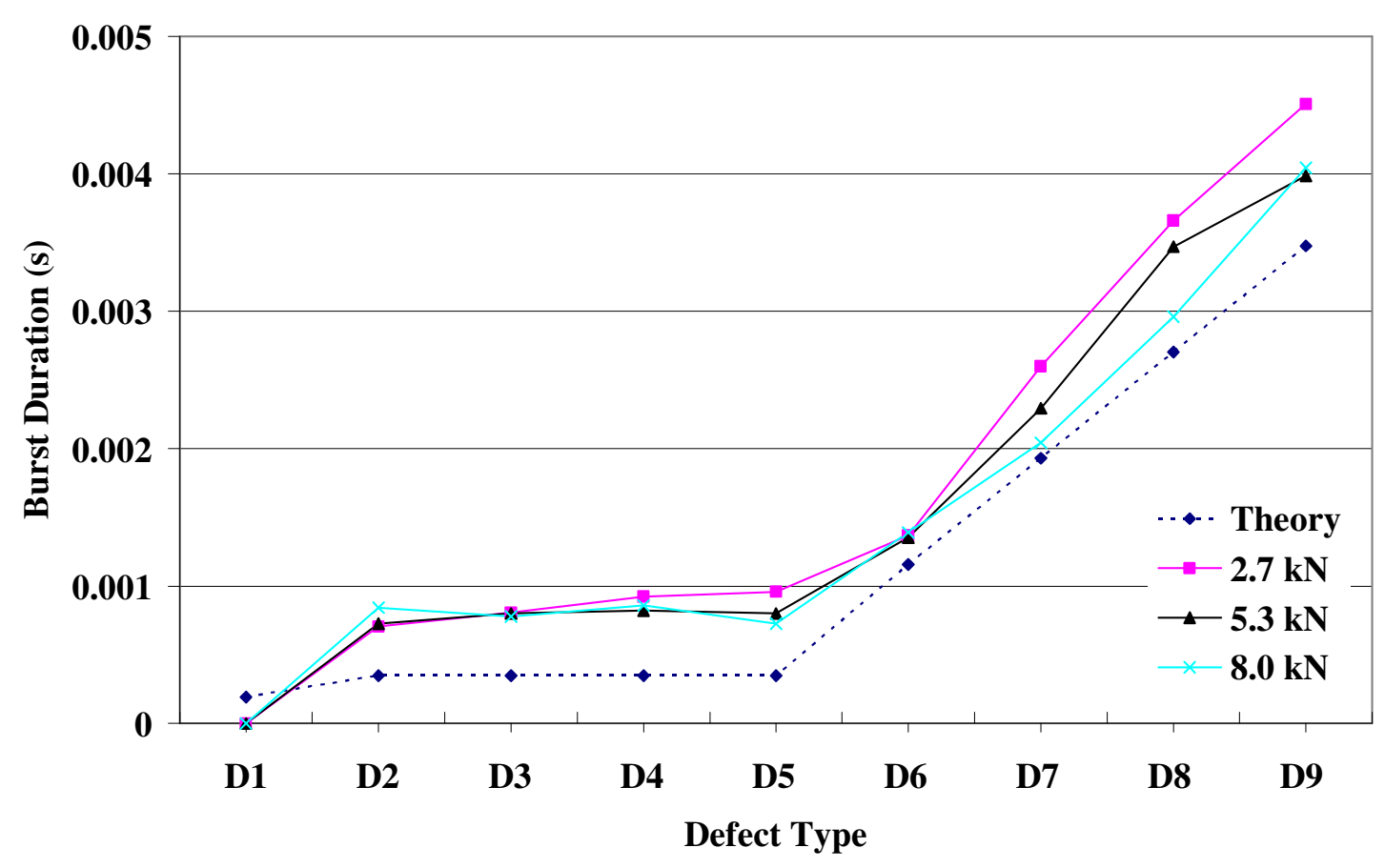

Figure 13 Burst Duration at 1500rpm; outer race defect

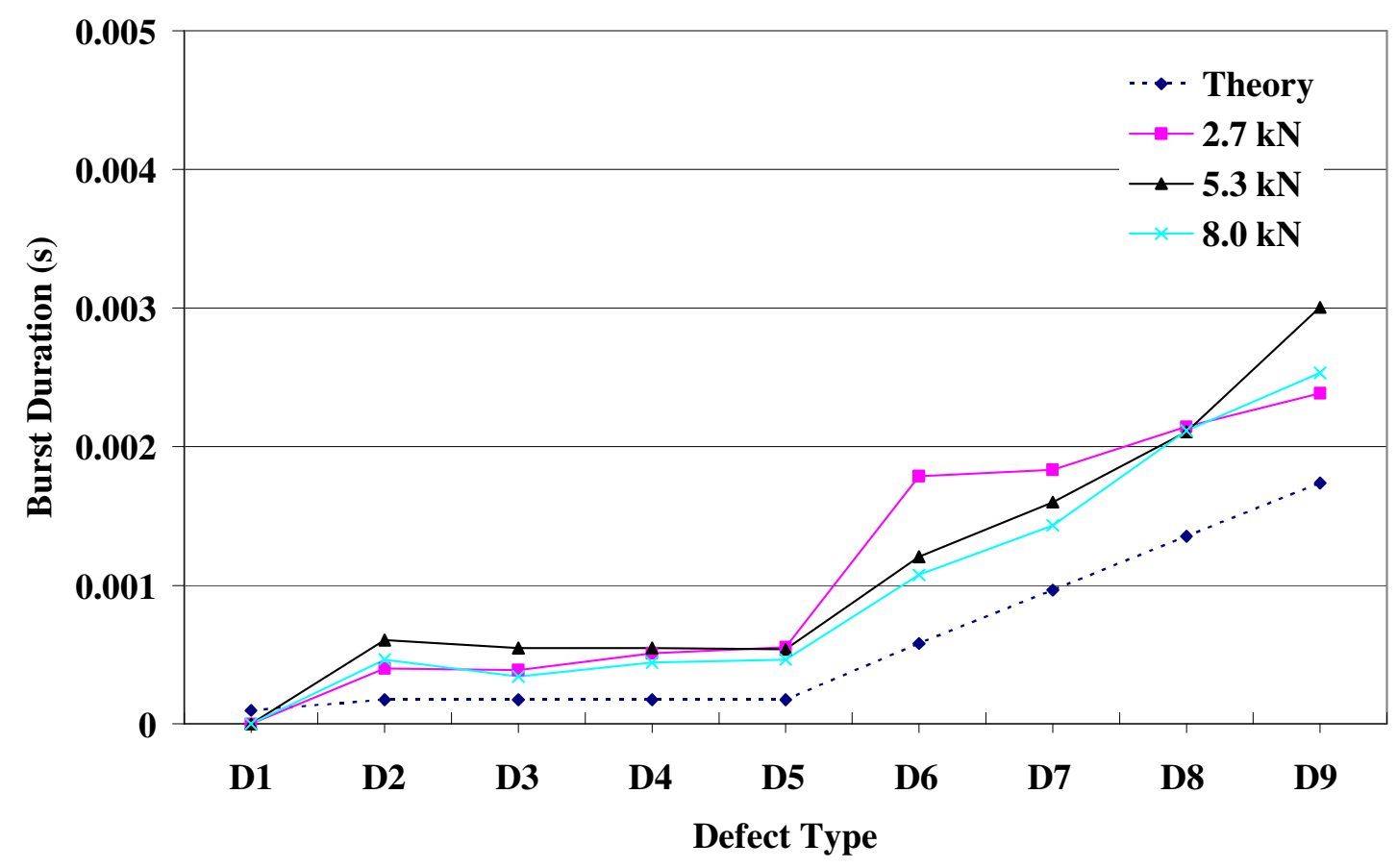

Figure 14 Burst Duration at 3000rpm; outer race defect

The theoretical time duration of the roller passing over the defect was also calculated based on the rotational speed of the shaft and the relative velocities of the elements 
within the bearing. The objective was to correlate the theoretically determined time duration over which the roller passed the defect to the duration of $\mathrm{AE}$ transient burst associated with the specified defect assuming no cage slip. Comparative results of theoretical and experimental values are presented in figures 13 and 14. All experimental values of $\mathrm{AE}$ burst duration for both speed conditions were larger than the calculated theoretical values by as much as $60 \%$ for specific defects associated with increasing width (D1 to D5) and in the order of 22\% and 37\% (for $1500 \mathrm{rpm}$ and $3000 \mathrm{rpm}$ respectively) for defects of increasing length; see tables 2 and 3. This suggested that the measured experimental burst duration was more representative of the defect size for conditions were the discrimination of the start and end of the defect were more evident (D6-D9). A reason for the difference between theoretical and experimental time durations is attributed to the decay characteristics of the $\mathrm{AE}$ transient bursts. The selected end position of the AE transient is not actually the instant in time when the generation of AE ceased as there is an exponential decay associated with $\mathrm{AE}$ transient bursts. The selected end position of the $\mathrm{AE}$ burst associated with the defect includes this decay time. To reduce the difference between the theoretical and experimental results will require employing much higher sampling rates to aid discrimination. A couple of other factors will have contributed to this difference include the tolerance of the geometric defect size and the slight variation in rotational speed of the motor. Observations of figures 13 and 14 also revealed that load had relatively no influence on the AE burst duration associated with the defect.

Table 2 Experimental and theoretical AE burst duration at 1500rpm

(Outer race)

\begin{tabular}{|c|c|c|c|c|c|c|c|}
\hline \multirow{2}{*}{ Defect } & \multirow{2}{*}{ Theory } & \multicolumn{3}{|c|}{ Burst Duration } & \multicolumn{3}{c|}{ \% Difference } \\
\cline { 3 - 7 } & & $2.7 \mathrm{kN}$ & $5.3 \mathrm{kN}$ & $8 \mathrm{kN}$ & $2.7 \mathrm{kN}$ & $5.3 \mathrm{kN}$ & $8 \mathrm{kN}$ \\
\hline
\end{tabular}




\begin{tabular}{|l|c|c|c|c|c|c|c|} 
D1 & $1.93 \mathrm{E}-04$ & $0.00 \mathrm{E}+00$ & $0.00 \mathrm{E}+00$ & $0.00 \mathrm{E}+00$ & & & \\
\hline D2 & $3.48 \mathrm{E}-04$ & $7.06 \mathrm{E}-04$ & $7.27 \mathrm{E}-04$ & $8.44 \mathrm{E}-04$ & $50.7 \%$ & $50.7 \%$ & $52.2 \%$ \\
\hline D3 & $3.48 \mathrm{E}-04$ & $8.07 \mathrm{E}-04$ & $8.00 \mathrm{E}-04$ & $7.78 \mathrm{E}-04$ & $56.9 \%$ & $56.9 \%$ & $56.5 \%$ \\
\hline D4 & $3.48 \mathrm{E}-04$ & $9.24 \mathrm{E}-04$ & $8.22 \mathrm{E}-04$ & $8.58 \mathrm{E}-04$ & $62.4 \%$ & $62.4 \%$ & $57.7 \%$ \\
\hline D5 & $3.48 \mathrm{E}-04$ & $9.60 \mathrm{E}-04$ & $8.00 \mathrm{E}-04$ & $7.27 \mathrm{E}-04$ & $63.8 \%$ & $63.8 \%$ & $56.6 \%$ \\
\hline D6 & $1.16 \mathrm{E}-03$ & $1.37 \mathrm{E}-03$ & $1.35 \mathrm{E}-03$ & $1.39 \mathrm{E}-03$ & $15.3 \%$ & $15.3 \%$ & $14.4 \%$ \\
\hline D7 & $1.93 \mathrm{E}-03$ & $2.60 \mathrm{E}-03$ & $2.29 \mathrm{E}-03$ & $2.04 \mathrm{E}-03$ & $25.7 \%$ & $25.7 \%$ & $15.8 \%$ \\
\hline D8 & $2.70 \mathrm{E}-03$ & $3.66 \mathrm{E}-03$ & $3.47 \mathrm{E}-03$ & $2.96 \mathrm{E}-03$ & $26.1 \%$ & $26.1 \%$ & $22.1 \%$ \\
\hline D9 & $3.48 \mathrm{E}-03$ & $4.51 \mathrm{E}-03$ & $3.99 \mathrm{E}-03$ & $4.04 \mathrm{E}-03$ & $22.9 \%$ & $22.9 \%$ & $12.8 \%$ \\
\hline
\end{tabular}

Table 3 Experimental and theoretical AE burst duration at 3000rpm

\section{(Outer race)}

\begin{tabular}{|c|c|c|c|c|c|c|c|}
\hline \multirow{2}{*}{ Defect } & \multirow{2}{*}{ Theory } & \multicolumn{3}{|c|}{ Burst Duration } & \multicolumn{3}{c|}{ \% Difference } \\
\cline { 3 - 8 } & & $\mathbf{2 . 7} \mathbf{~ k N}$ & $\mathbf{5 . 3} \mathbf{~ k N}$ & $\mathbf{8 ~ k N}$ & $\mathbf{2 . 7} \mathbf{~ k N}$ & $\mathbf{5 . 3 ~ k N}$ & $\mathbf{8 ~ k N}$ \\
\hline D1 & $9.65 \mathrm{E}-05$ & $0.00 \mathrm{E}+00$ & $0.00 \mathrm{E}+00$ & $0.00 \mathrm{E}+00$ & & & \\
\hline D2 & $1.74 \mathrm{E}-04$ & $4.00 \mathrm{E}-04$ & $6.04 \mathrm{E}-04$ & $4.65 \mathrm{E}-04$ & $56.6 \%$ & $71.2 \%$ & $62.7 \%$ \\
\hline D3 & $1.74 \mathrm{E}-04$ & $3.89 \mathrm{E}-04$ & $5.46 \mathrm{E}-04$ & $3.42 \mathrm{E}-04$ & $55.3 \%$ & $68.1 \%$ & $49.2 \%$ \\
\hline D4 & $1.74 \mathrm{E}-04$ & $5.09 \mathrm{E}-04$ & $5.45 \mathrm{E}-04$ & $4.44 \mathrm{E}-04$ & $65.9 \%$ & $68.1 \%$ & $60.8 \%$ \\
\hline D5 & $1.74 \mathrm{E}-04$ & $5.53 \mathrm{E}-04$ & $5.38 \mathrm{E}-04$ & $4.66 \mathrm{E}-04$ & $68.6 \%$ & $67.7 \%$ & $62.7 \%$ \\
\hline D6 & $5.79 \mathrm{E}-04$ & $1.79 \mathrm{E}-03$ & $1.21 \mathrm{E}-03$ & $1.08 \mathrm{E}-03$ & $67.6 \%$ & $52.0 \%$ & $46.2 \%$ \\
\hline D7 & $9.65 \mathrm{E}-04$ & $1.83 \mathrm{E}-03$ & $1.60 \mathrm{E}-03$ & $1.43 \mathrm{E}-03$ & $47.3 \%$ & $39.7 \%$ & $32.6 \%$ \\
\hline D8 & $1.35 \mathrm{E}-03$ & $2.15 \mathrm{E}-03$ & $2.11 \mathrm{E}-03$ & $2.12 \mathrm{E}-03$ & $37.0 \%$ & $35.9 \%$ & $36.1 \%$ \\
\hline D9 & $1.74 \mathrm{E}-03$ & $2.39 \mathrm{E}-03$ & $3.00 \mathrm{E}-03$ & $2.53 \mathrm{E}-03$ & $27.2 \%$ & $42.2 \%$ & $31.4 \%$ \\
\hline
\end{tabular}

The observations of $\mathrm{AE}$ burst duration associated with the inner race highlighted variations from theoretical estimates of up to $80 \%$ (see tables 4 and 5) for defects with increasing length and in excess of $350 \%$ for defects with increasing width. However, it was noted that as the length of the inner race defect increased D18 to D19, and, D19 to D20, the percentage error between theoretical and experimentally measured durations increased significantly. This was not observed for outer race defects (D6 to 
D9) where errors remained, on average, at $22 \%$. The reduced error for increasing lengths was also noted for the outer race defect. Also as noted for the outer race there was no influence of load on the AE burst duration, see figures 15 and 16 . Whilst the results detailed on $\mathrm{AE}$ burst duration are specific to bearings -1 and -3 , the same observations were noted for bearings -2 and -4 .

Table 4 Experimental and theoretical AE burst duration at 1500rpm (Inner race)

\begin{tabular}{|c|c|c|c|c|c|c|c|}
\hline \multirow{2}{*}{ Defect } & \multirow{2}{*}{ Theory } & \multicolumn{3}{|c|}{ Burst Duration } & \multicolumn{3}{c|}{ \% Difference } \\
\cline { 3 - 8 } & & $\mathbf{2 . 7} \mathbf{~ k N}$ & $\mathbf{5 . 3} \mathbf{~ k N}$ & $\mathbf{8 ~ k N}$ & $\mathbf{2 . 7} \mathbf{~ k N}$ & $\mathbf{5 . 3 ~ k N}$ & $\mathbf{8 ~ k N}$ \\
\hline D17 & $2.71 \mathrm{E}-04$ & $0.00 \mathrm{E}+00$ & $0.00 \mathrm{E}+00$ & $0.00 \mathrm{E}+00$ & & & \\
\hline D18 & $1.62 \mathrm{E}-03$ & $1.27 \mathrm{E}-03$ & $1.51 \mathrm{E}-03$ & $1.38 \mathrm{E}-03$ & $28.3 \%$ & $7.5 \%$ & $17.7 \%$ \\
\hline D19 & $3.25 \mathrm{E}-03$ & $1.71 \mathrm{E}-03$ & $1.73 \mathrm{E}-03$ & $1.86 \mathrm{E}-03$ & $89.4 \%$ & $87.6 \%$ & $74.4 \%$ \\
\hline D20 & $6.49 \mathrm{E}-03$ & $1.82 \mathrm{E}-03$ & $1.98 \mathrm{E}-03$ & $2.27 \mathrm{E}-03$ & $257.2 \%$ & $228.7 \%$ & $186.1 \%$ \\
\hline D21 & $6.49 \mathrm{E}-03$ & $1.80 \mathrm{E}-03$ & $1.65 \mathrm{E}-03$ & $1.75 \mathrm{E}-03$ & $261.5 \%$ & $293.7 \%$ & $271.6 \%$ \\
\hline D22 & $6.49 \mathrm{E}-03$ & $1.55 \mathrm{E}-03$ & $1.60 \mathrm{E}-03$ & $1.86 \mathrm{E}-03$ & $318.6 \%$ & $305.7 \%$ & $248.9 \%$ \\
\hline
\end{tabular}

Table 5 Experimental and theoretical AE burst duration at 3000rpm

(Inner race)

\begin{tabular}{|c|c|c|c|c|c|c|c|}
\hline \multirow{2}{*}{ Defect } & \multirow{2}{*}{ Theory } & \multicolumn{3}{|c|}{ Burst Duration } & \multicolumn{3}{c|}{ \% Difference } \\
\cline { 3 - 8 } & & $\mathbf{2 . 7} \mathbf{~ k N}$ & $\mathbf{5 . 3} \mathbf{~ k N}$ & $\mathbf{8 ~ k N}$ & $\mathbf{2 . 7} \mathbf{~ k N}$ & $\mathbf{5 . 3} \mathbf{~ k N}$ & $\mathbf{8 ~ k N}$ \\
\hline D17 & $1.36 \mathrm{E}-04$ & $0.00 \mathrm{E}+00$ & $0.00 \mathrm{E}+00$ & $0.00 \mathrm{E}+00$ & & & \\
\hline D18 & $8.13 \mathrm{E}-04$ & $8.98 \mathrm{E}-04$ & $1.04 \mathrm{E}-03$ & $1.05 \mathrm{E}-03$ & $9.4 \%$ & $21.6 \%$ & $22.8 \%$ \\
\hline D19 & $1.63 \mathrm{E}-03$ & $1.16 \mathrm{E}-03$ & $1.06 \mathrm{E}-03$ & $1.18 \mathrm{E}-03$ & $40.3 \%$ & $53.3 \%$ & $38.4 \%$ \\
\hline
\end{tabular}




\begin{tabular}{|l|l|l|l|l|l|l|l|} 
D20 & $3.25 \mathrm{E}-03$ & $7.18 \mathrm{E}-04$ & $8.65 \mathrm{E}-04$ & $8.74 \mathrm{E}-04$ & $352.9 \%$ & $276.0 \%$ & $272.4 \%$ \\
\hline D21 & $3.25 \mathrm{E}-03$ & $1.21 \mathrm{E}-03$ & $9.55 \mathrm{E}-04$ & $9.89 \mathrm{E}-04$ & $168.0 \%$ & $240.7 \%$ & $229.1 \%$ \\
\hline D22 & $3.25 \mathrm{E}-03$ & $1.14 \mathrm{E}-03$ & $7.10 \mathrm{E}-04$ & $9.80 \mathrm{E}-04$ & $184.6 \%$ & $358.2 \%$ & $232.1 \%$ \\
\hline
\end{tabular}

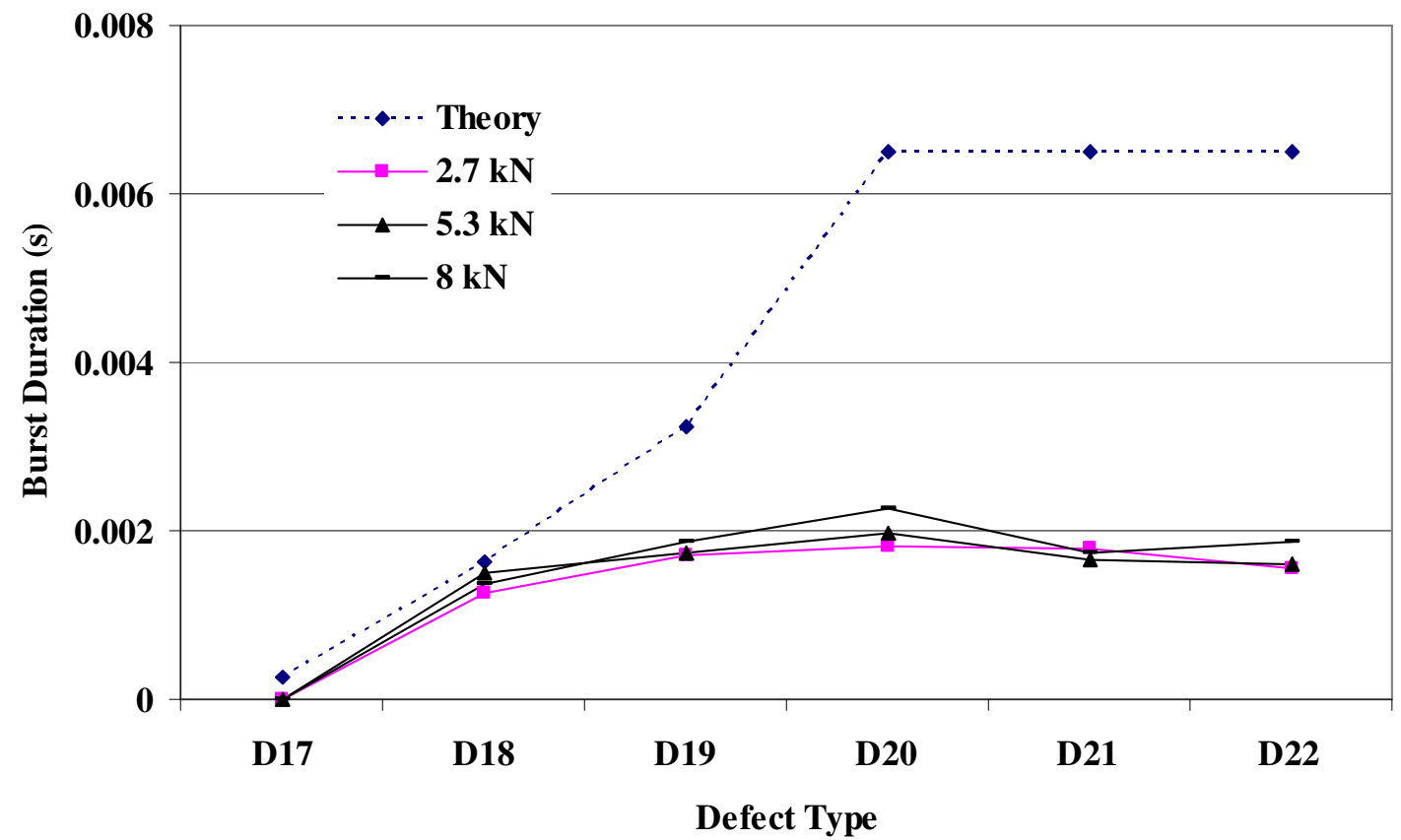

Figure 15 Burst Duration at 1500rpm; inner race defect

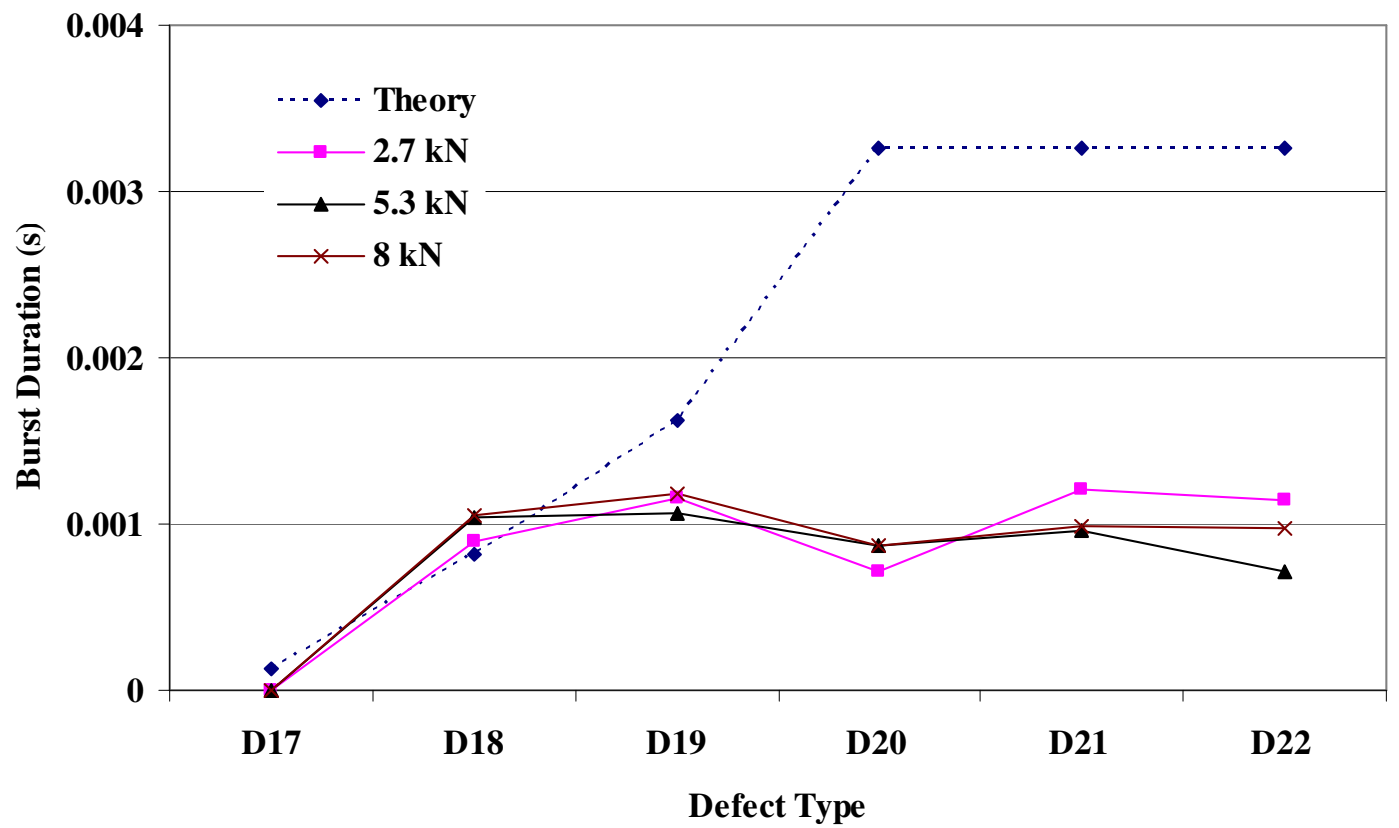

Figure 16 Burst Duration at 3000rpm; inner race defect 
Another observation made during this experiment was that in several instances the AE burst associated with a defect condition had, in some instances, two large AE 'spikes'; one at the instant in time when the roller entered or made contact with the defect and the second as the roller exited the defect, see figure 17. It is postulated that this observation can be correlated to the method of artificially seeding the fault onto the rolling elements, see figure 18 . This technique of seeding the defect introduced large protrusion at the edge of the defect. It is postulated that these protrusions were responsible for the peaks at the start and end of the burst.

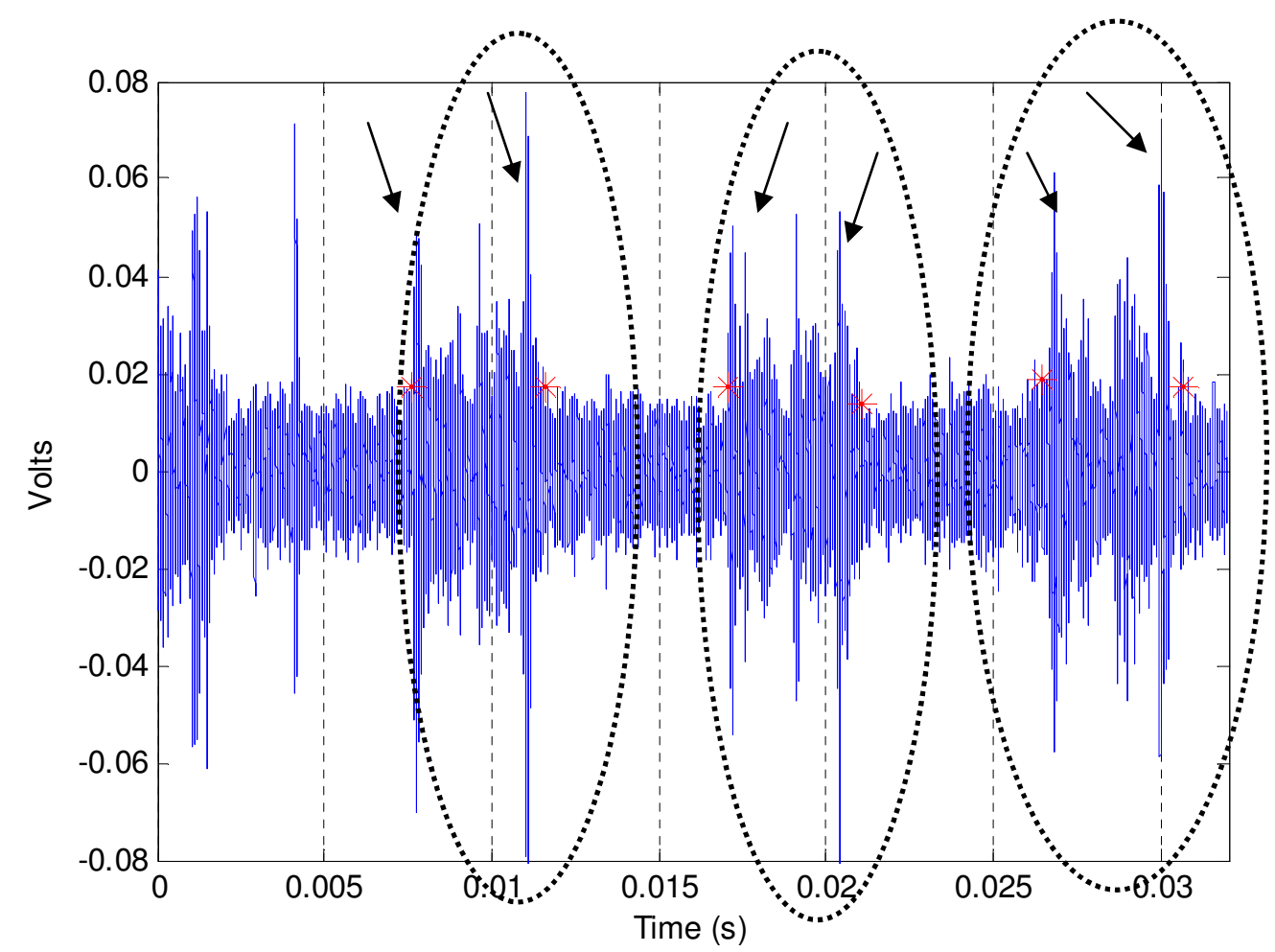

Figure 17 AE transient bursts from a defect condition showing two large AE spikes which are postulated to be from the roller's entry and exit from the defect 

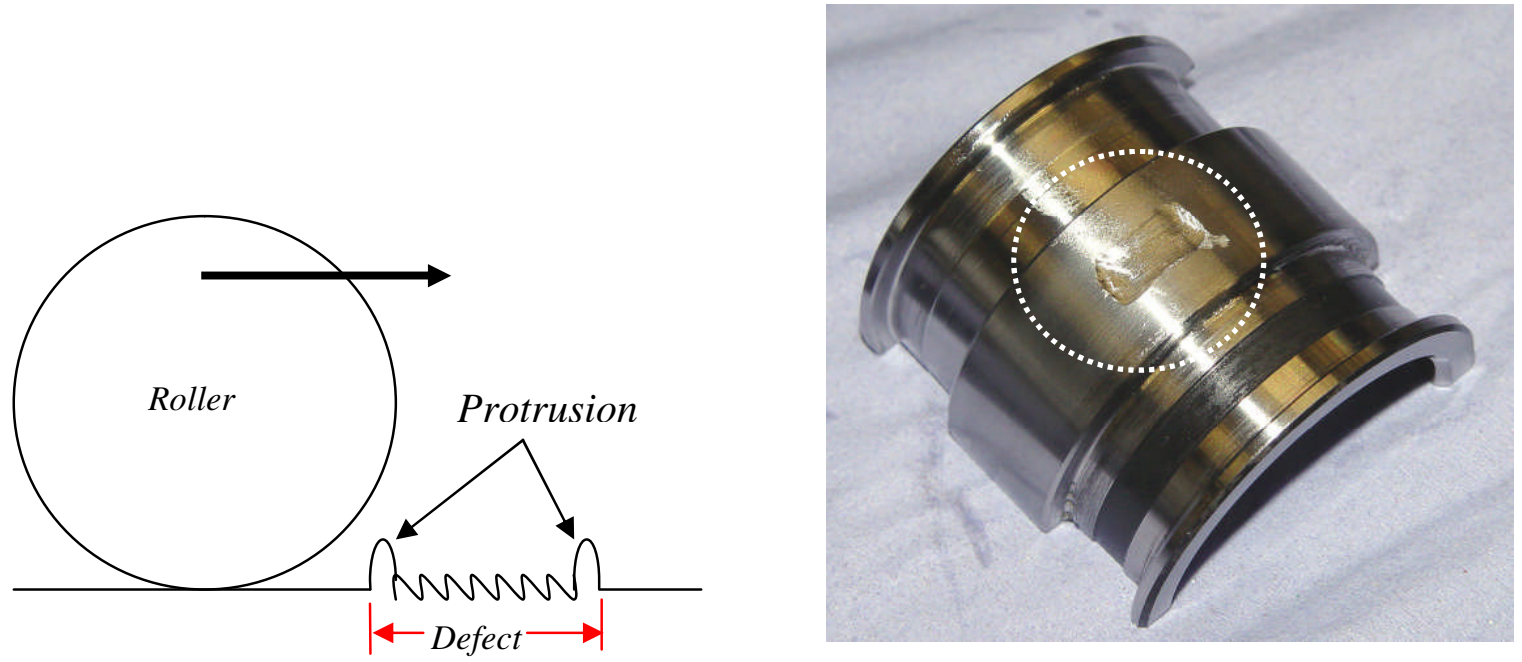

Figure 18 Schematic, and pictorial view, showing entry and exit surface condition on seeded defect

\subsection{Observations of AE burst to noise ratio (D1-D9)}

The ratio of maximum $\mathrm{AE}$ burst amplitude to the underlying operational noise levels was determined and correlated to the seeded defect width. Observations of the AE transient burst to noise ratio for outer race defects showed an increase with increasing defect width (D1 to D5), however, it was also noted that an increase in defect length, for a constant defect width (D6-D9), did not change the burst to noise ratio, see figures 19, 20 and table 6 . For the inner race defects the trend in burst-to-noise ratio noted on the outer race was not replicated, see figures 21,22 and table 7; the pattern noted for the inner was random. It was again noted that load had a relatively insignificant influence on this ratio for outer race defect conditions only. 
Table 6 AE burst-to-noise ratios for outer race defects

\begin{tabular}{|c|c|c|c|c|c|c|c|}
\hline \multicolumn{4}{|c|}{ 1500rpm } & \multicolumn{4}{|c|}{$3000 \mathrm{rpm}$} \\
\hline Defect & $2.7 \mathrm{kN}$ & $5.3 \mathrm{kN}$ & 8 kN & Defect & $2.7 \mathrm{kN}$ & $5.3 \mathrm{kN}$ & $8 \mathrm{kN}$ \\
\hline D1 & 0.00 & 0.00 & 0.00 & D1 & 0.00 & 0.00 & 0.00 \\
\hline D2 & 4.66 & 4.38 & 5.10 & D2 & 4.37 & 3.28 & 2.90 \\
\hline D3 & 4.22 & 3.90 & 4.88 & D3 & 4.17 & 4.28 & 4.18 \\
\hline D4 & 4.83 & 4.84 & 5.21 & D4 & 5.51 & 5.04 & 5.23 \\
\hline D4 & 7.37 & 7.48 & 6.73 & D4 & 6.75 & 9.16 & 6.87 \\
\hline D6 & 6.86 & 7.58 & 7.24 & D6 & 7.73 & 7.26 & 7.30 \\
\hline D7 & 4.88 & 5.19 & 6.28 & D7 & 5.89 & 6.81 & 5.78 \\
\hline D8 & 4.05 & 5.77 & 5.85 & D8 & 6.01 & 7.60 & 5.73 \\
\hline D9 & 7.61 & 5.73 & 5.32 & D9 & 10.56 & 7.42 & 5.72 \\
\hline
\end{tabular}

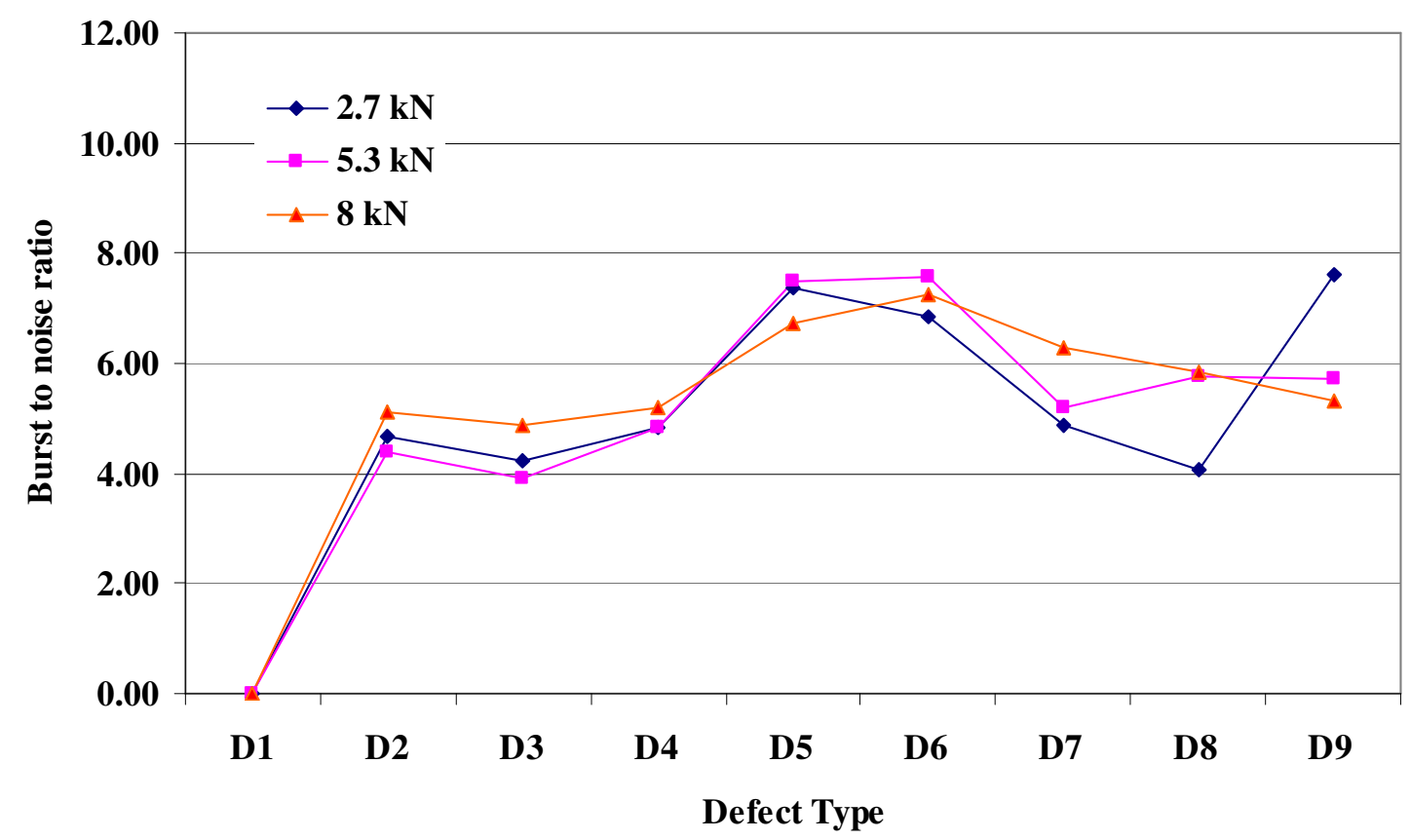

Figure 19 AE burst to noise ratio at 1500rpm (outer race defect) 


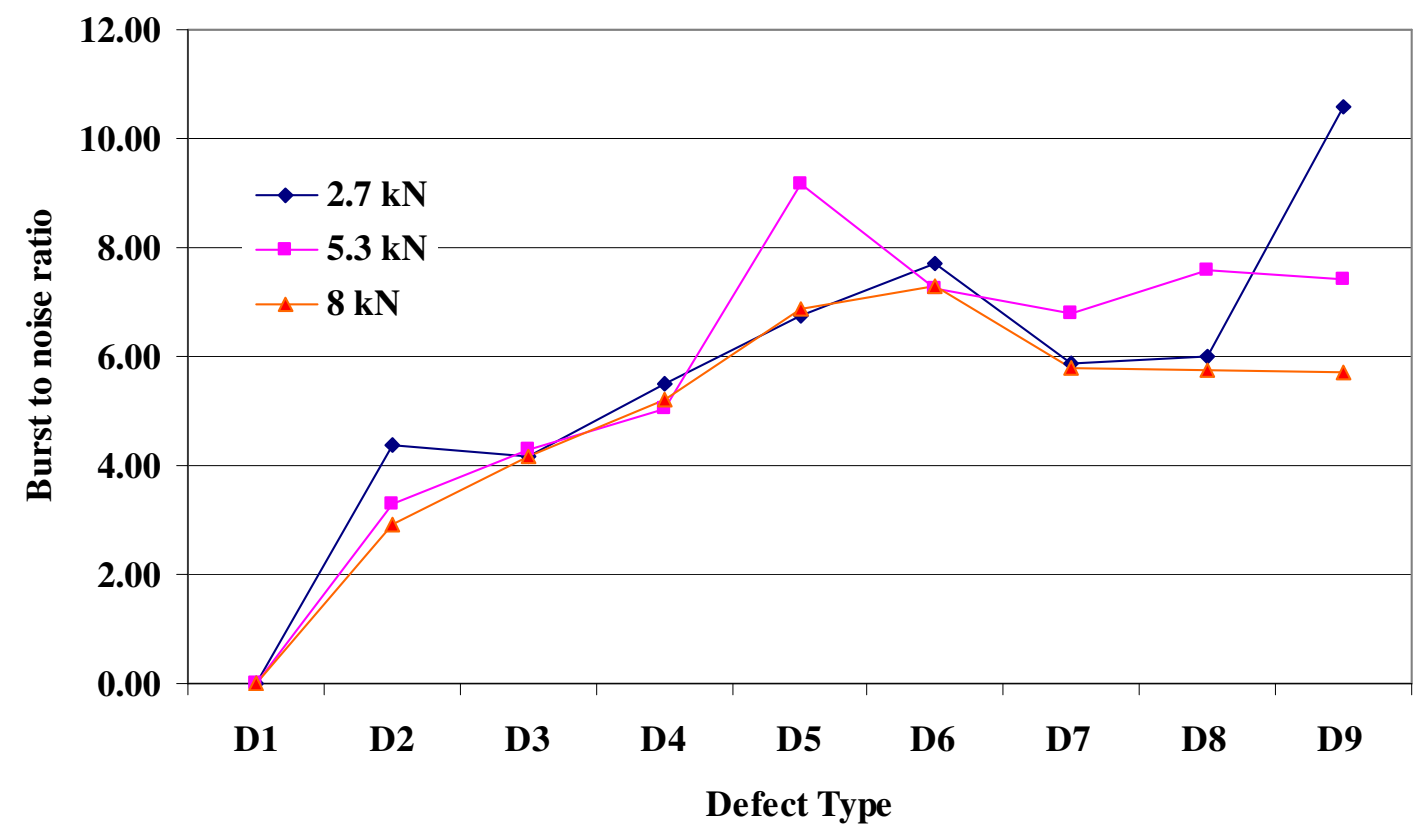

Figure 20 AE burst to noise ratio at 3000rpm (Outer race defect)

Table 7 AE burst-to-noise ratios for inner race defects

\begin{tabular}{|c|c|c|c|c|c|c|c|}
\hline \multicolumn{4}{|c|}{ 1500rpm } & \multicolumn{4}{|c|}{3000 rpm } \\
\hline Defect & $2.7 \mathrm{kN}$ & $5.3 \mathrm{kN}$ & $8 \mathrm{kN}$ & Defect & $2.7 \mathrm{kN}$ & $5.3 \mathrm{kN}$ & $8 \mathrm{kN}$ \\
\hline D17 & 0.00 & 0.00 & 0.00 & D17 & 0.00 & 0.00 & 0.00 \\
\hline D18 & 10.19 & 13.03 & 11.55 & D18 & 6.12 & 13.60 & 7.03 \\
\hline D19 & 5.66 & 8.28 & 11.22 & D19 & 43.08 & 5.99 & 7.47 \\
\hline D20 & 9.40 & 4.51 & 10.69 & D20 & 3.53 & 10.30 & 8.26 \\
\hline D21 & 5.75 & 6.58 & 7.73 & D21 & 34.69 & 6.06 & 5.38 \\
\hline D22 & 5.58 & 4.91 & 1.20 & D22 & 22.83 & 25.87 & 12.03 \\
\hline
\end{tabular}




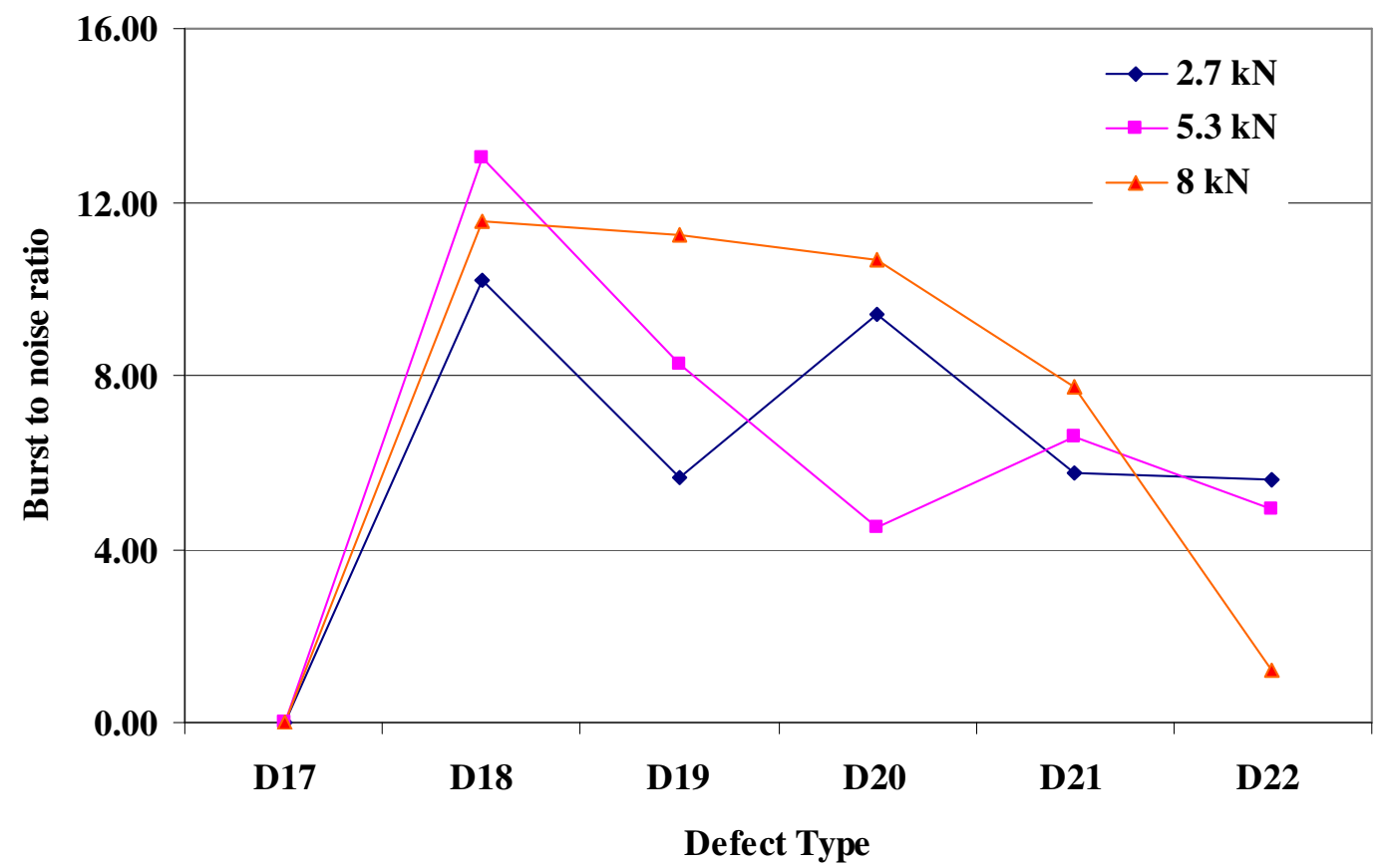

Figure 21 AE burst to noise ratio at 1500rpm (Inner race defect)

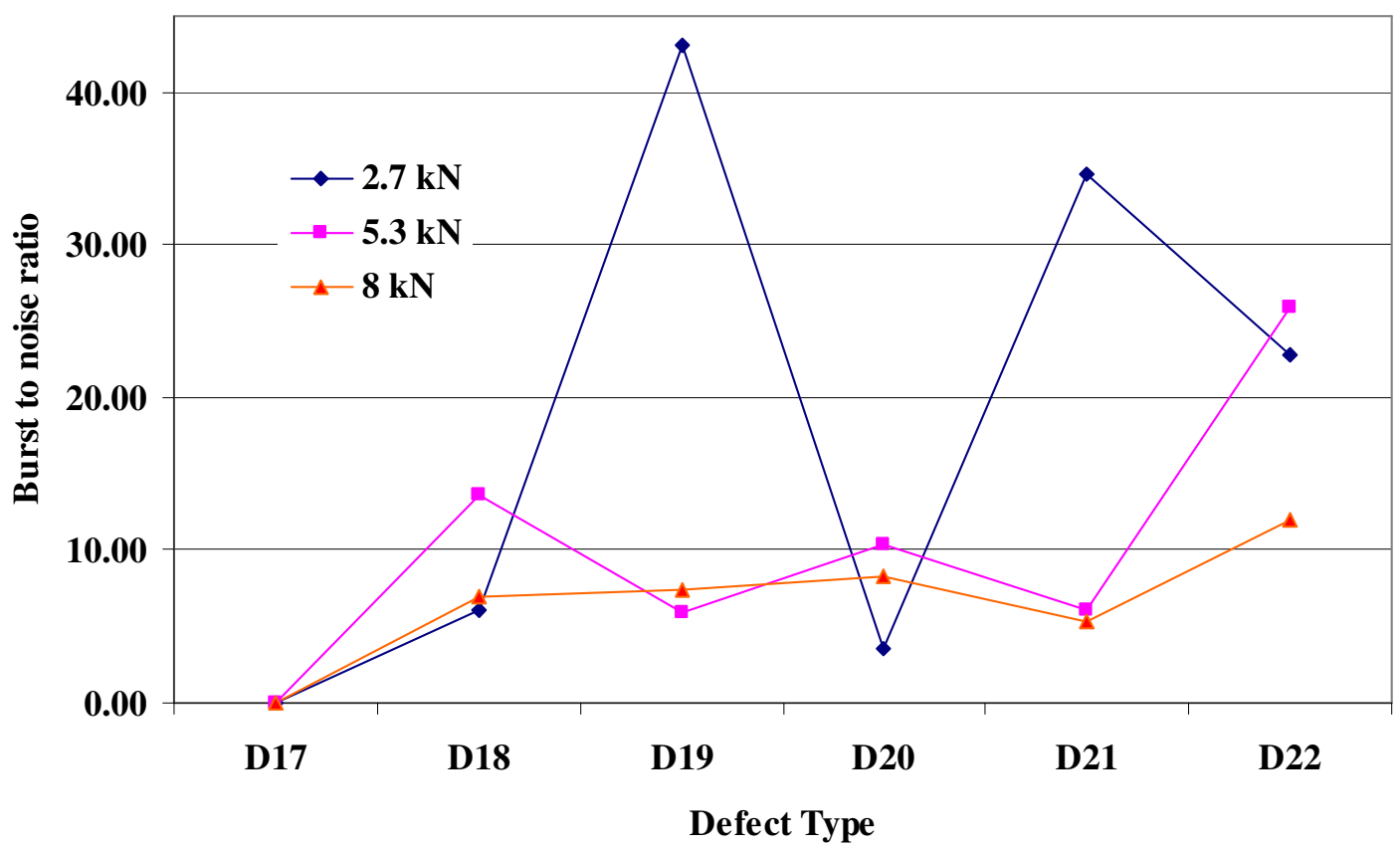

Figure $22 \mathrm{AE}$ burst to noise ratio at 3000rpm (Inner race defect) 


\section{Discussion and conclusions}

An increase in defect size resulted in an increase in levels of AE energy for outer and inner race seeded defects. This was also noted for AE maximum amplitude values for outer race defects, however, this was not the case for inner race defects. The reason is attributed to the variation in transmission path from the AE source (inner race) to the AE sensor on the bearing casing. This partly supports the findings of other researchers $[2,3]$ and highlights that monitoring inner race defects by observations of $\mathrm{AE}$ maximum amplitude from a sensor located on the bearing housing can fraught with difficulty. This is further highlighted by observations of figure 23 where three data files for the same defect, speed and load condition showed quite distinct characteristics; the figure shows $\mathrm{AE}$ transient bursts associated with the inner race defect however the rate at which the bursts occurred was not always equivalent to the inner race defect frequency, moreover the rates varied for the same test condition as shown in figure 23. This is attributed to the attenuation of the AE signatures as a direct consequence of the variation in the transmission with circumferential position of the rolling elements within the bearing. From this investigation it would appear that the AE energy values determined over a period equivalent to approximately 1.6 shaft revolutions can offer an indication of increasing inner race defect severity provided an adequate number of samples are taken; in this instance 42 data files equivalent to just over 67 revolution was employed for each test condition.. 

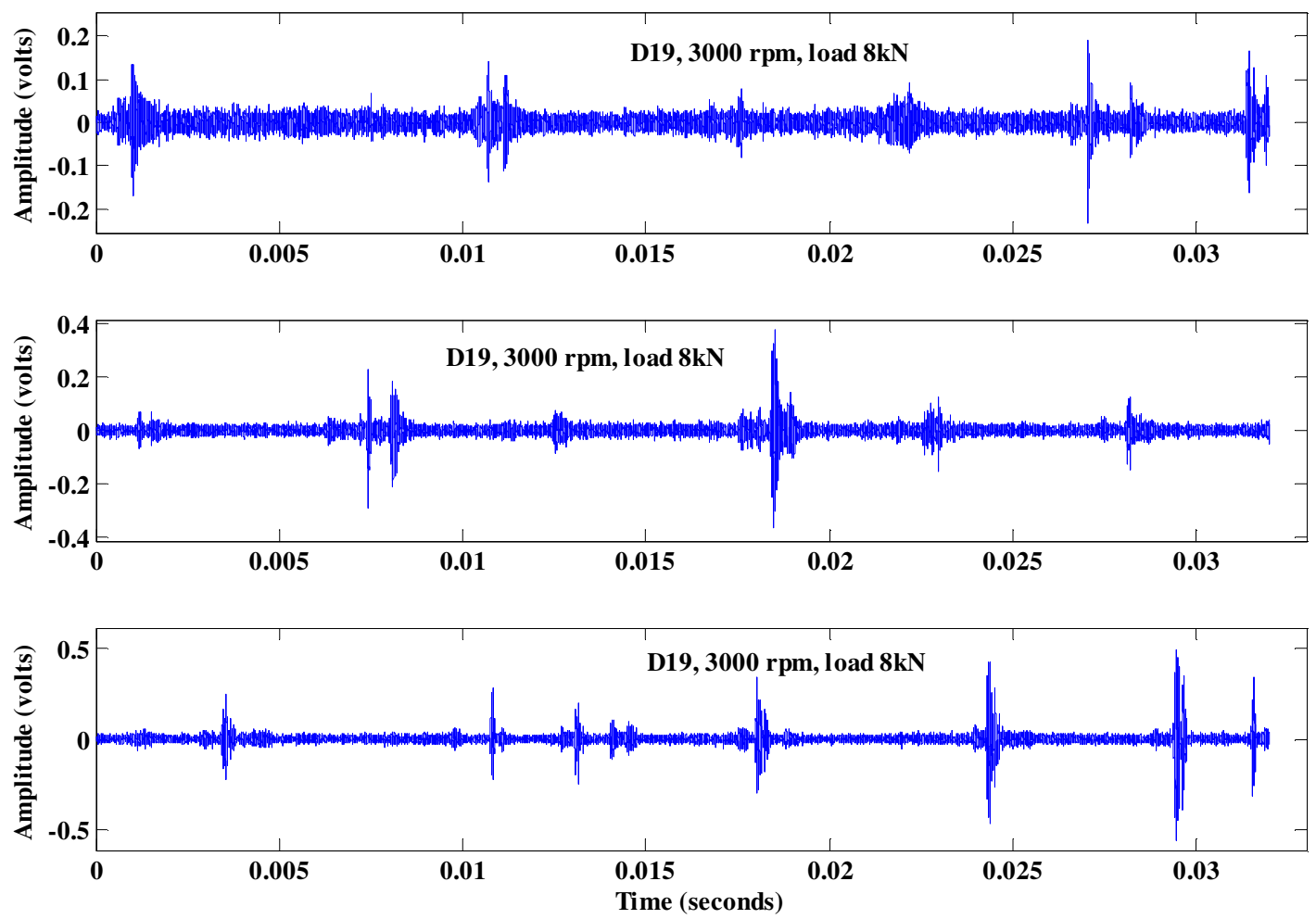

\section{Figure 23 AE waveforms associated with an inner race defect $(3000 \mathrm{rpm})$}

It was also noted, for both defect conditions, that the time duration between successive AE transients were not always identical. For instance, figure 24 shows an outer race defect condition at $3000 \mathrm{rpm}$ with a difference in time interval between some of the successive AE bursts. This variation is attributed to slip of the cage assembly. This observation was also noted for inner race defects, see figure 25 , where the top plot shows a variation in the time duration between successive AE transients while the bottom plot of figure 25 shows the near constant time intervals between successive AE bursts attributed to the inner race defect. These observations also offer an explanation why the number of $\mathrm{AE}$ transients did not match the theoretical defect frequency. For example, the lower plot of figure 25 shows approximately $8.5 \mathrm{AE}$ 
transient burst over $32 \mathrm{mseconds}$; the theoretical estimate was calculated at 9.3 ; this would suggest a slip factor of 0.9 .

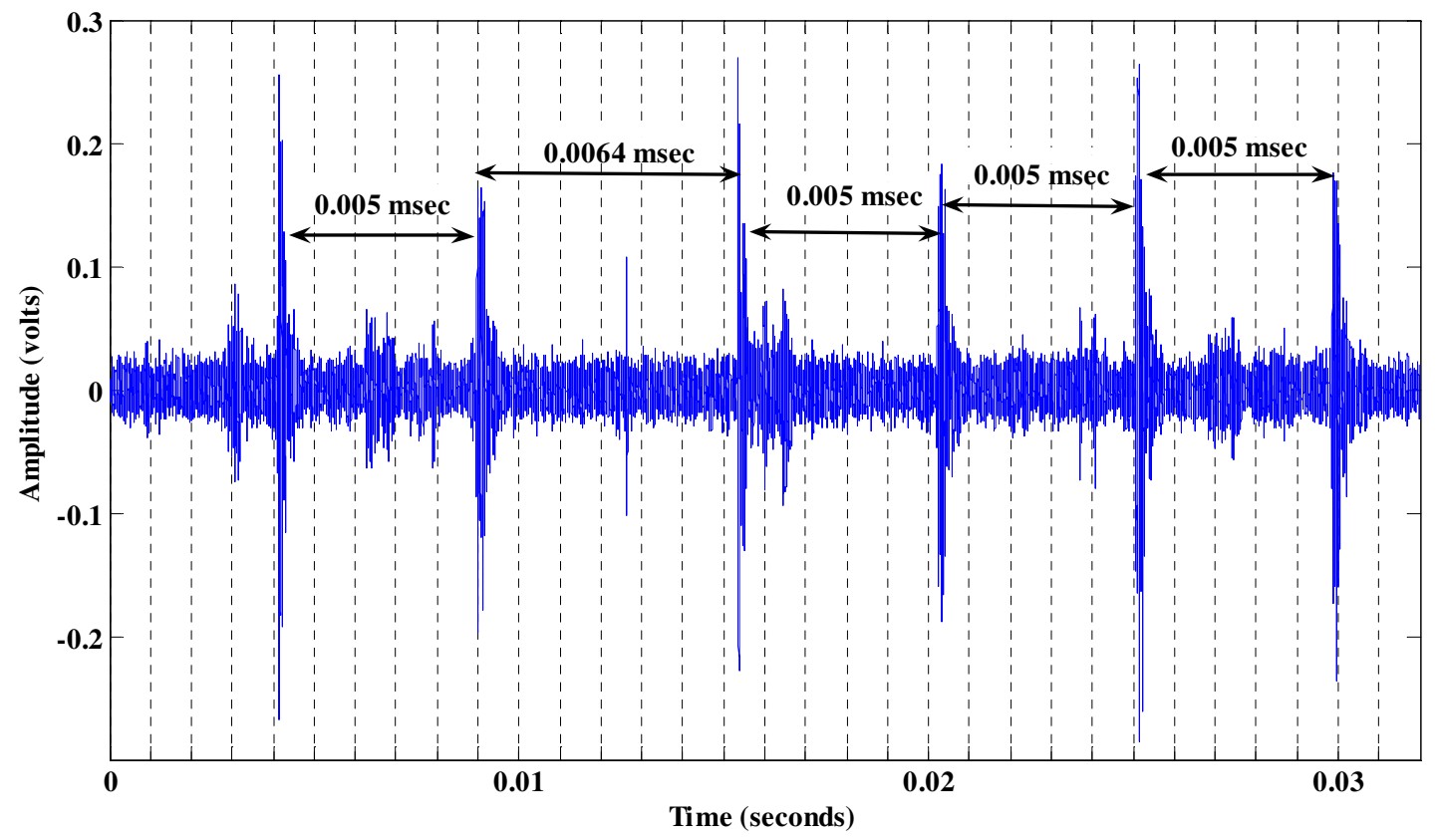

Figure 24 Evidence of cage slip due to the variation in time interval between successive AE bursts (Outer race defect, 3000 rpm) 

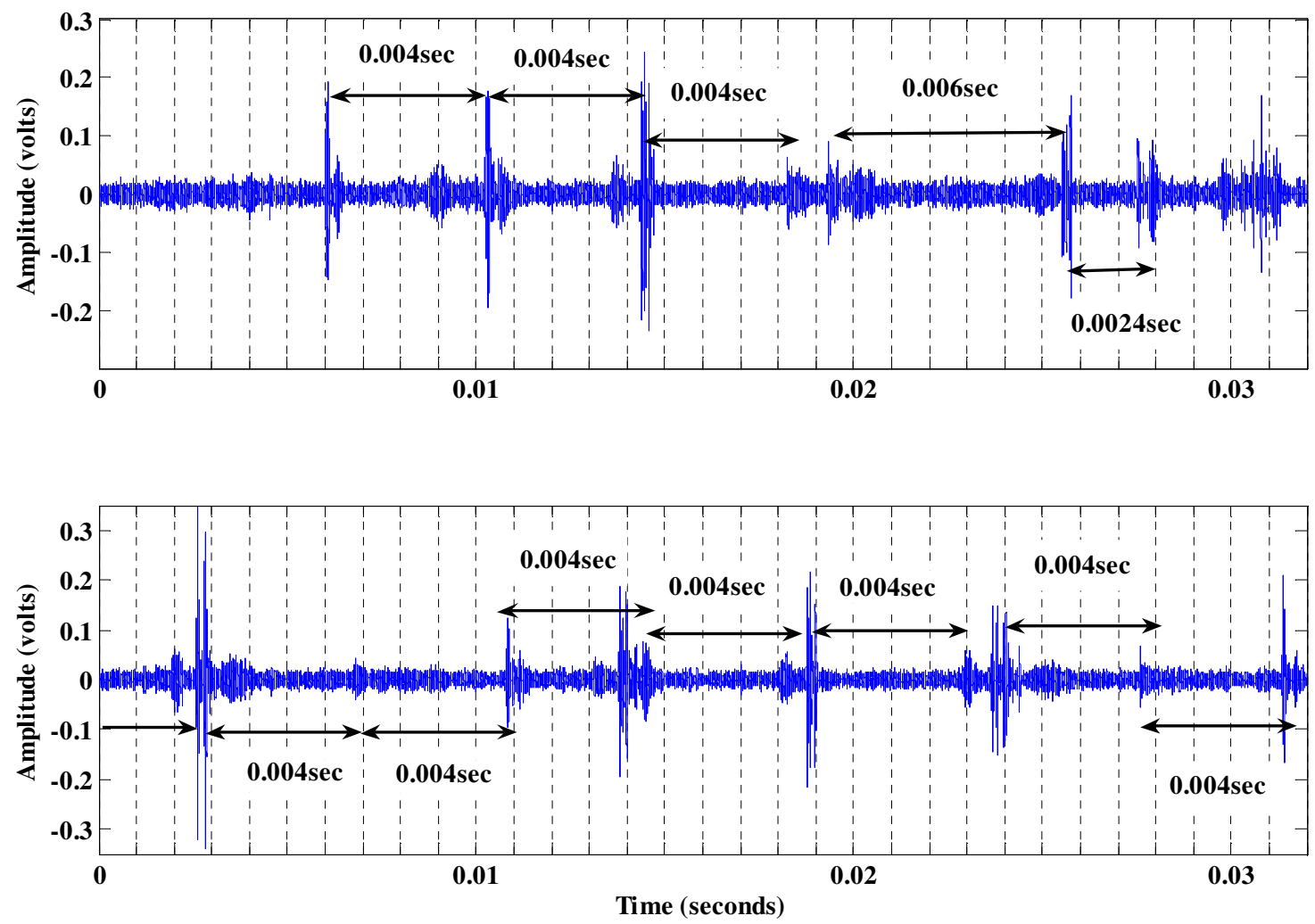

Figure 25 Evidence of cage slip due to the variation in time interval between successive AE bursts (Inner race defect, 3000 rpm)

An increase in the outer race defect length resulted in an increase in $\mathrm{AE}$ transient burst duration associated with the particular defect. An increase in the width of the outer race defect resulted in an increase in ratio between the maximum amplitude of the AE transient burst for the defect to the underlying operational noise levels. This observation was noted for bearings -1 and -2 . Appendix A details a summary of some of the results and presents $\mathrm{AE}$ waveforms, giving the reader an appreciation of the changes of the $\mathrm{AE}$ waveform with defect size. A relationship between $\mathrm{AE}$ burst duration nor maximum amplitude to noise ratio for inner race defects was not established and this was attributed to the variation in transmission path with angular position of the shaft and bearing elements. For any future investigation it is advised 
that a trigger mechanism be employed to ensure that the acquired $\mathrm{AE}$ can be related to the inner race defect within the load zone, ensuring a much improved transmission path to the receiving $\mathrm{AE}$ sensor. However, this highlights a limitation in actual operational conditions where the position of inner race defects will be unknown.

In conclusion, the measurement of $\mathrm{AE}$ energy over a duration equivalent to just over one rotation of the shaft has been shown to offer an indication of increasing defect severity for outer and inner race defects. A correlation between the geometric size of outer race defects and the $\mathrm{AE}$ bursts associated with such defects has been shown however, this does not apply to inner race defects. The relationship between defect size and $\mathrm{AE}$ burst duration is a significant finding which in the longer term, and with further research, offers opportunities for prognosis.

\section{References}

1. D. Mba \& Raj B.K.N. Rao, Development of Acoustic Emission Technology for Condition Monitoring and Diagnosis of Rotating Machines; Bearings, Pumps, Gearboxes, Engines and Rotating Structures. The Shock and Vibration digest, 38/1, Jan 2006, 3-16.

2. J. Shiroishi, Y. Li, S. Liang, T. Kurfess and S, Danyluk, Bearing condition diagnostics via vibration and acoustic emission measurements, Mechanical Systems and Signal Processing, V 11, N 5, 1997, p. 697-705.

3. Chee Keong Tan and David Mba, Limitation of Acoustic Emission for identifying seeded defects in gearboxes. Journal of Nondestructive Evaluation, Vol. 24, No. 1, March 2005, p 11 - 28. ISSN: 0195-9298. 
4. Balerston, H. L., The detection of incipient failure in bearings, Materials Evaluation, Vol 27, 121-128, 1969.

5. Rogers, L. M., The application of vibration analysis and acoustic emission source location to on-line condition monitoring of anti-friction bearings. Tribology International, 1979; 51-59.

6. Yoshioka T, Fujiwara T. New acoustic emission source locating system for the study of rolling contact fatigue, Wear, 81(1), 183-186.

7. Yoshioka T, Fujiwara T. Application of acoustic emission technique to detection of rolling bearing failure, American Society of Mechanical Engineers, Production Engineering Division publication PED, 1984, 14, $55-76$.

8. Hawman, M. W., Galinaitis, W. S, Acoustic Emission monitoring of rolling element bearings, Proceedings of the IEEE, Ultrasonics symposium, 1988, 885-889

9. Holroyd, T.J. and Randall, N., (1993), Use of Acoustic Emission for Machine Condition Monitoring, British Journal of Non-Destructive Testing, 1993, 35(2), 75-78.

10. Holroyd, T. Condition monitoring of very slowly rotating machinery using AE techniques. 14th International congress on Condition monitoring and Diagnostic engineering management (COMADEM'2001), Manchester, UK, 46 September 2001, 29, ISBN 0080440363

11. Bagnoli, S., Capitani, R. and Citti, P. Comparison of accelerometer and acoustic emission signals as diagnostic tools in assessing bearing. Proceedings of 2nd International Conference on Condition Monitoring, London, UK, May $1988,117-125$. 
12. Tandon, N. and Nakra, B.C, Defect Detection of Rolling Element Bearings by Acoustic Emission Method, Journal of Acoustic Emission, 1990; 9(1) 25-28.

13. Choundhury, A. and Tandon, N., Application of acoustic emission technique for the detection of defects in rolling element bearings, Tribology International, 2000; 33, 39-45

14. Tan, C.C. Application of acoustic emission to the detection of bearing failures. The Institution of Engineers Australia, Tribology conference, Brisbane, 3-5 December 1990, 110-114.

15. Huguet, S, Godin, N, Gaertner, R, Salmon, L, Villard, D. Use of acoustic emission to identify damage modes in glass fibre reinforced polyester. Composites Science and Technology, 2002, 62, 1433-1444.

16. Yoshioka, T., korenaga, A., Mano, H. and Yamamoto, T. Diagnosis of rolling bearing by measuring time interval of Acoustic Emission generation. Journal of Tribology, Transactions of ASME, Vol. 121, July 1999, 468-472.

17. Morhain, A, Mba, D, Bearing defect diagnosis and acoustic emission, Journal of Engineering Tribology, I Mech E, Vol 217, No. 4, Part J, p 257-272, 2003. ISSN 1350-6501.

18. Abdullah M. Al-Ghamdi, P. Cole, Rafael Such, D. Mba, Estimation of bearing defect size with Acoustic Emission, INSIGHT, Vol. 46, no. 12, 758-761, Dec 2004.

19. Abdullah M. Al-Ghamdi and D. Mba. A comparative experimental study on the use of Acoustic Emission and vibration analysis for bearing defect identification and estimation of defect size. Mechanical Systems and Signal Processing, Accepted MSSP04-98R2. 2005. 

Table A1 : Outer Race Defect; 15001pm Load $2.7 \mathrm{kN}$

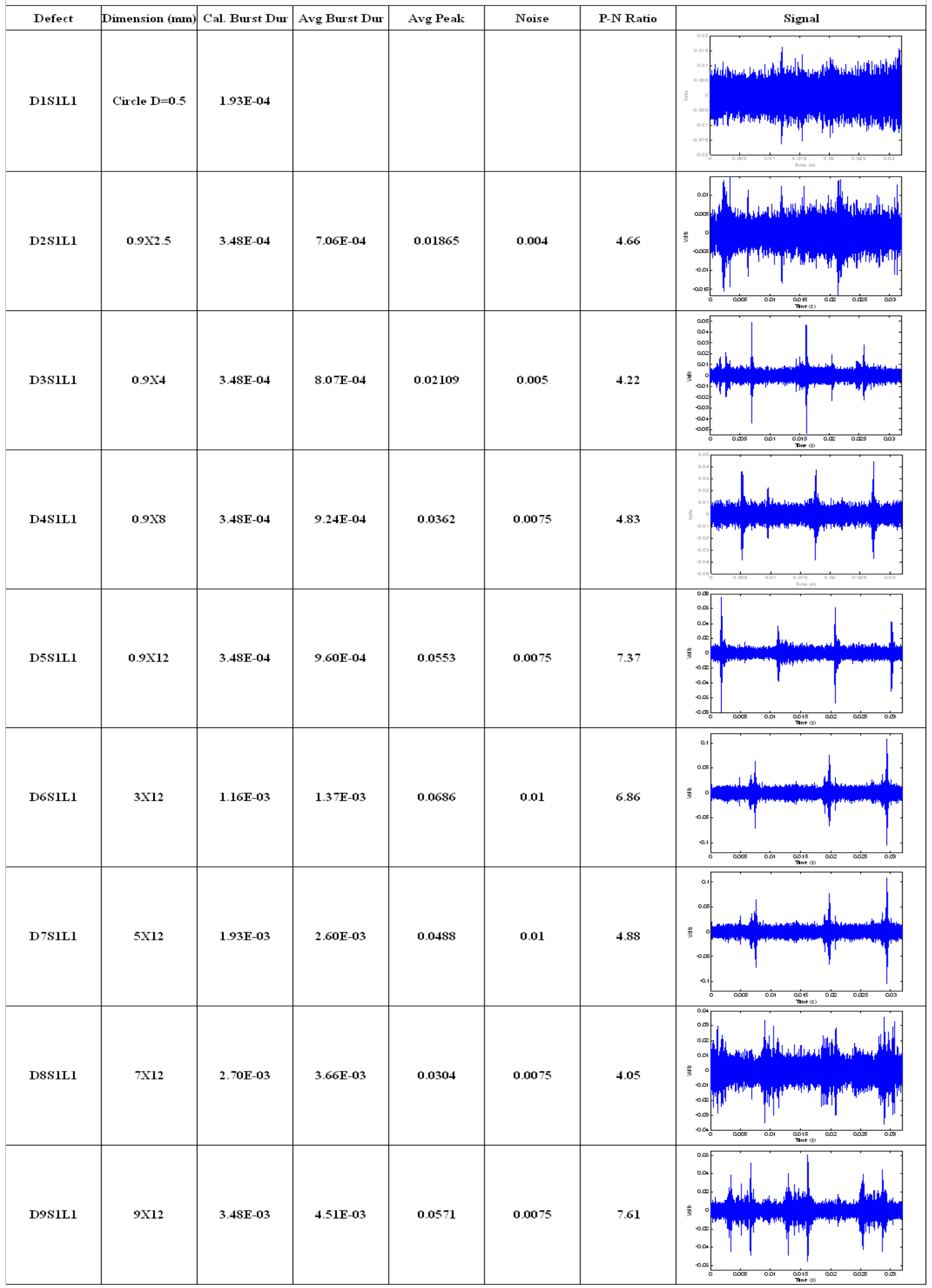


Table A2 : Outer Race Defect; 1500rpm Load 5.3kN

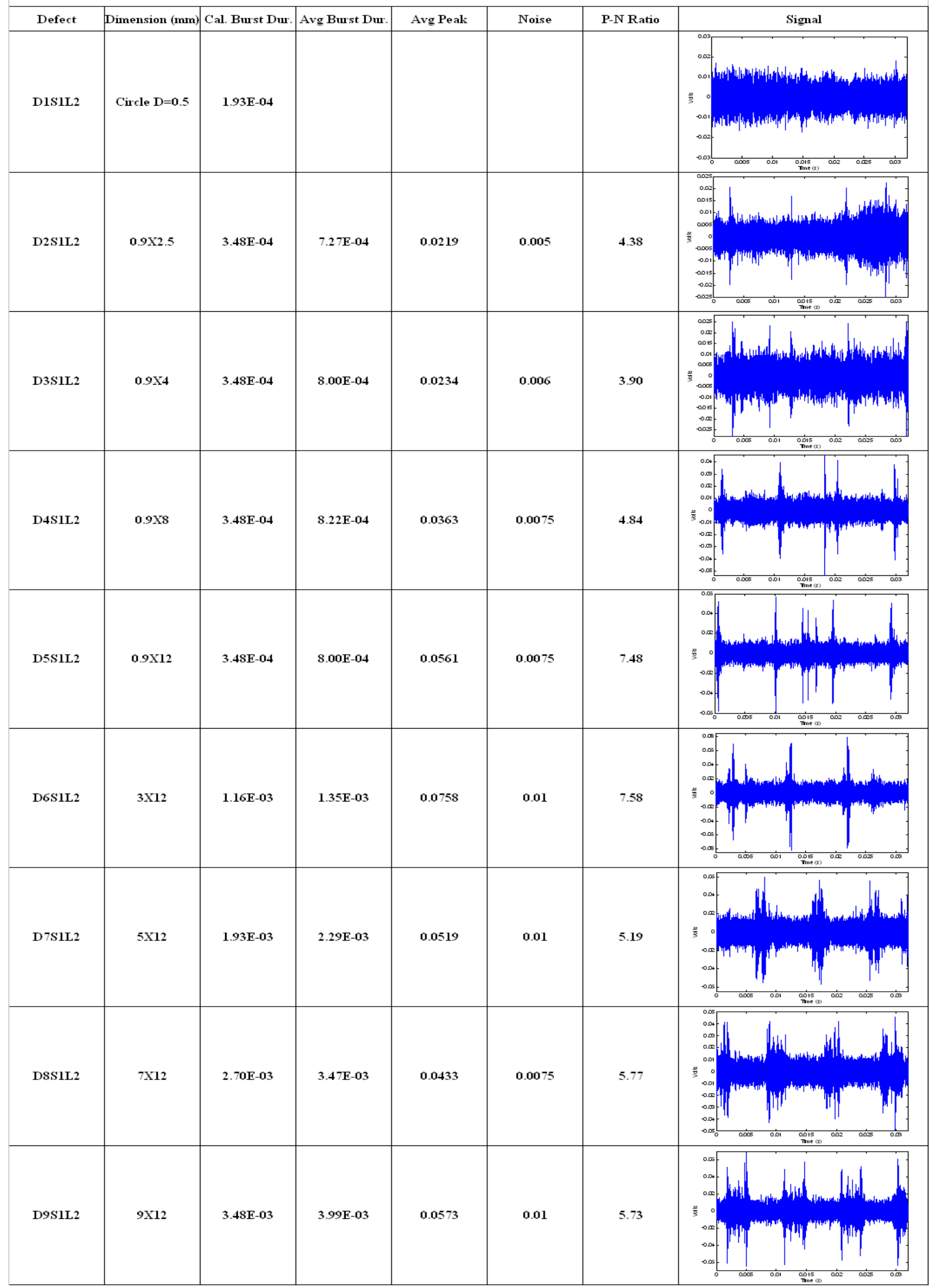


Table A3 : Outer Race Defect; 15001pm Load 8.0kN

\begin{tabular}{|c|c|c|c|c|c|c|c|}
\hline Defect & Dimension (mm) & Cal. Burst Dur & Avg Burst Dur & Avg Peak & Noise & P-N Ratio & Signal \\
\hline D1S1L3 & Circle $\mathrm{D}=0.5$ & $1.93 \mathrm{E}-04$ & & & & & 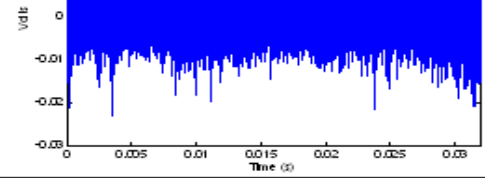 \\
\hline D2S1L3 & $0.9 \times 2.5$ & $3.48 \mathrm{E}-04$ & $8.44 \mathrm{E}-04$ & 0.0255 & 0.005 & 5.10 & 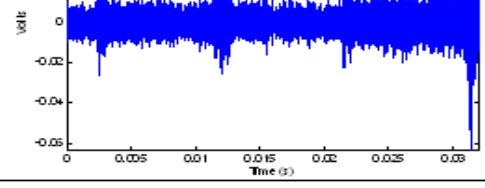 \\
\hline D3S1L3 & $0.9 \times 4$ & $3.48 E-04$ & $7.78 E-04$ & 0.0244 & 0.005 & 4.88 & 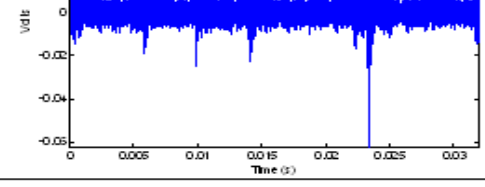 \\
\hline D4S1L3 & $0.9 \times 8$ & $3.48 \mathrm{E}-04$ & 8.58E-04 & 0.0391 & 0.0075 & 5.21 & $\underbrace{0.01}_{0.000}$ \\
\hline D5S1L3 & $0.9 \times 12$ & $3.48 \mathrm{E}-04$ & $7.27 \mathrm{E}-04$ & 0.0673 & 0.01 & 6.73 & (1) \\
\hline D6S1L3 & $3 \times 12$ & $1.16 \mathrm{E}-03$ & $1.39 \mathrm{E}-03$ & 0.0905 & 0.0125 & 7.24 & 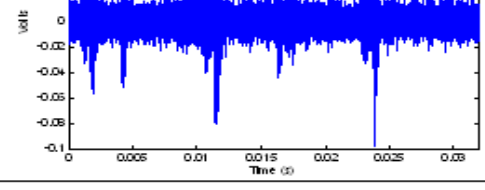 \\
\hline D7S1L3 & $5 \times 12$ & $1.93 \mathrm{E}-03$ & $2.04 \mathrm{E}-03$ & 0.0628 & 0.01 & 6.28 & 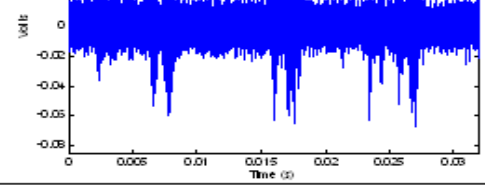 \\
\hline DSS1L3 & $7 \times 12$ & $2.70 \mathrm{E}-03$ & $2.96 \mathrm{E}-03$ & 0.0585 & 0.01 & 5.85 & 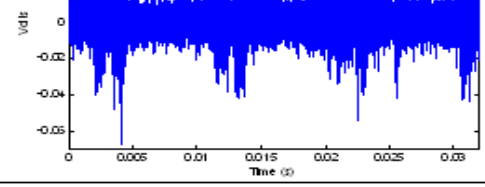 \\
\hline D9S1L3 & $9 \times 12$ & $3.48 E-03$ & $4.04 \mathrm{E}-03$ & 0.0665 & 0.0125 & 5.32 & 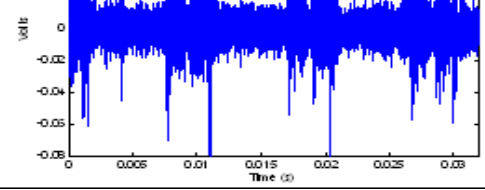 \\
\hline
\end{tabular}


Table A4 : Outer Race Defect; 30001pm Load 2.7kN

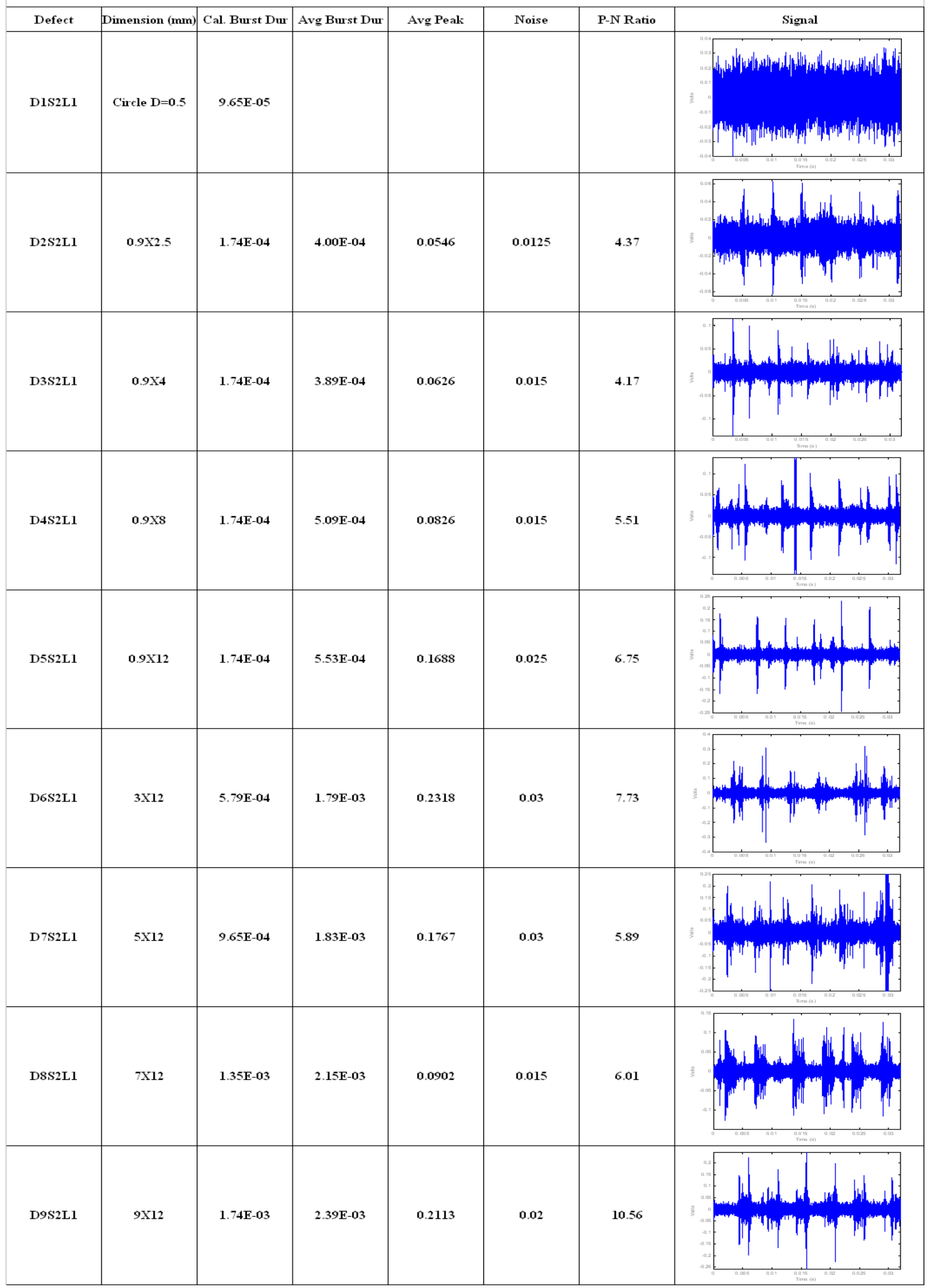


Table A5 : Outer Race Defect; 30001pm Load 5.3kN

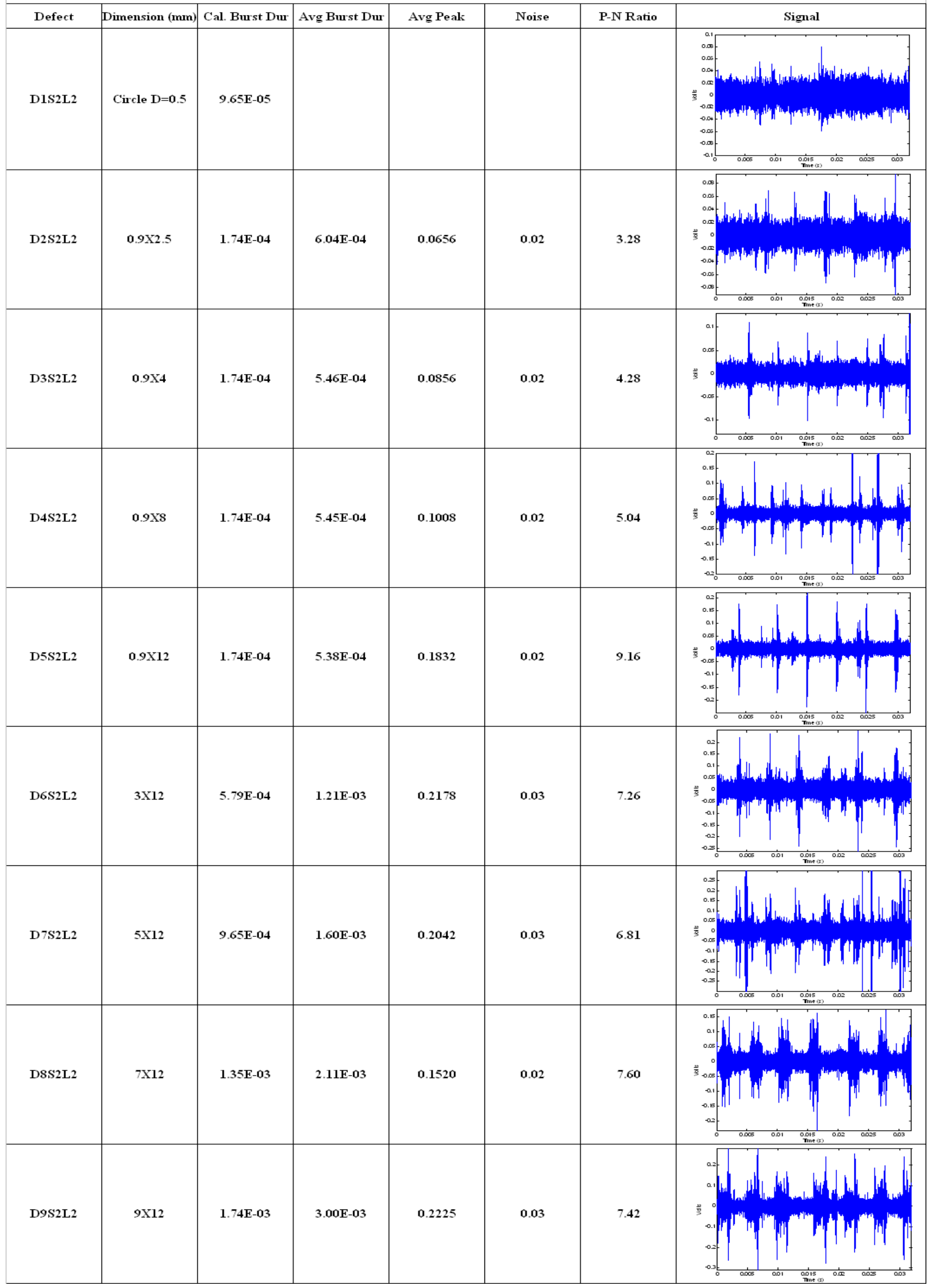


Table A6 : Outer Race Defect; 3000rpm Load 8.0kN

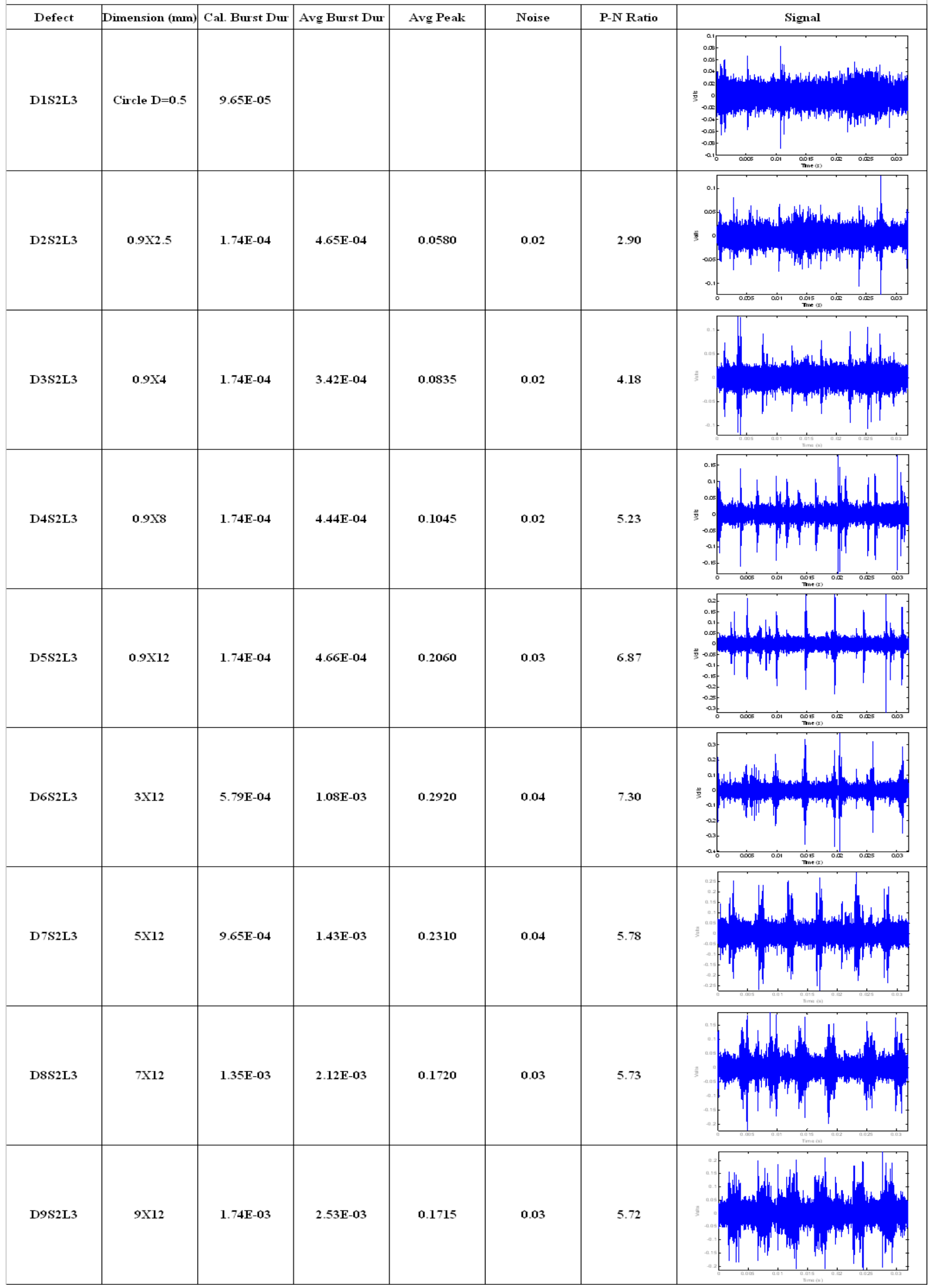


Table A7: Inner Race Defect; 1500rpm Load 2.7kN

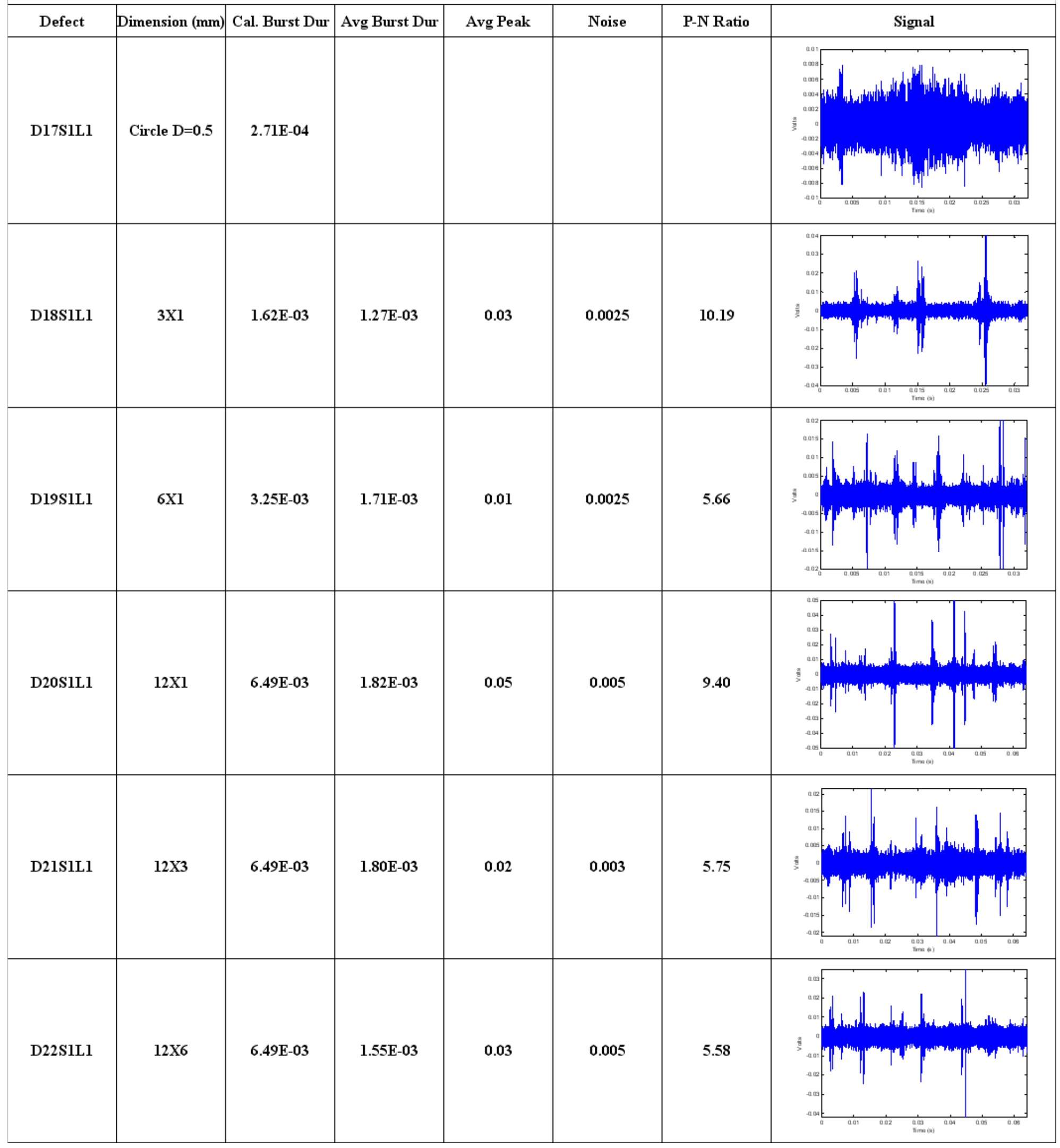


Table A8: Inner Race Defect; 15001pm Load 5.3kN

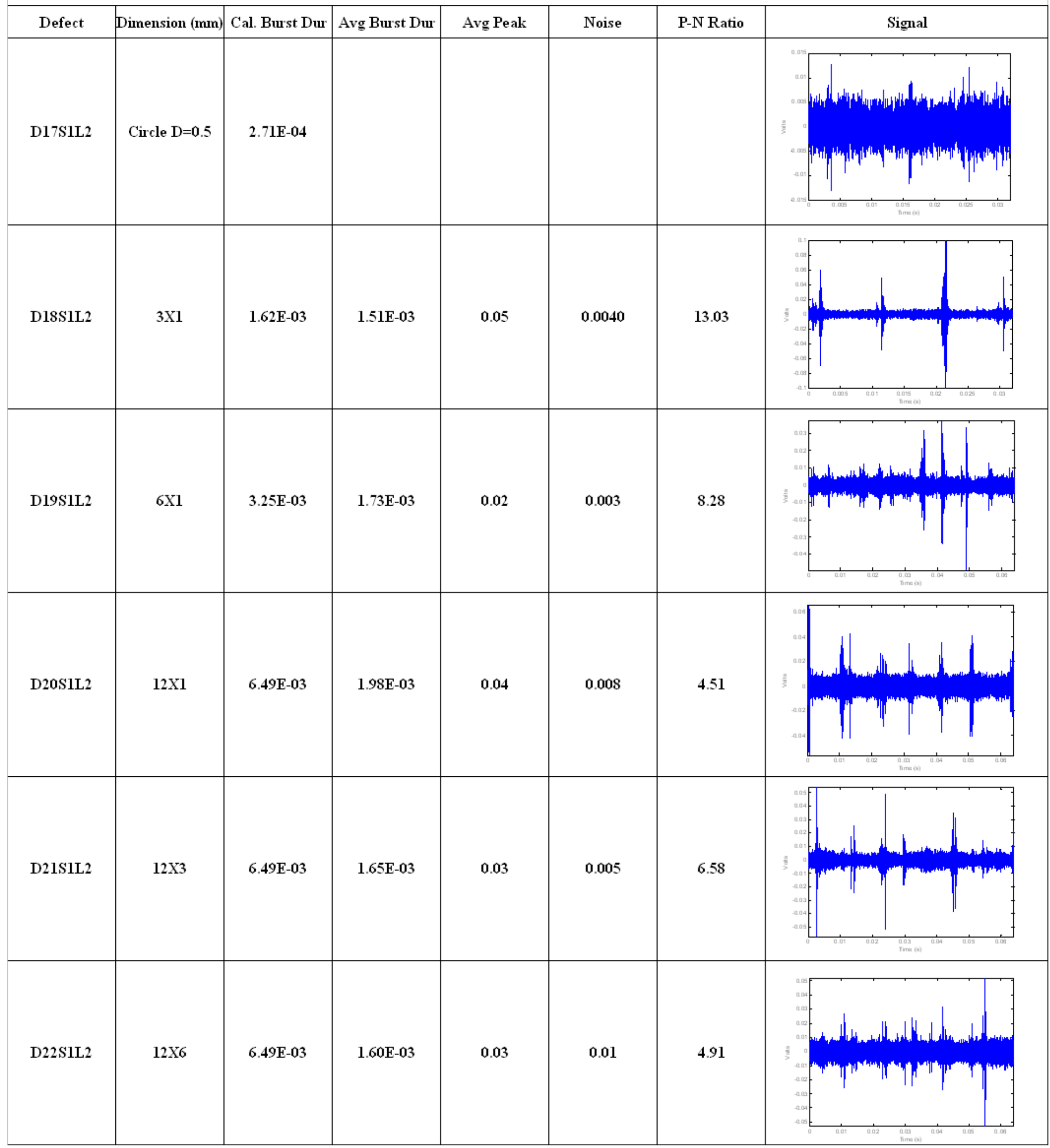


Table A9: Inner Race Defect; 1500rpm Load 8.0kN

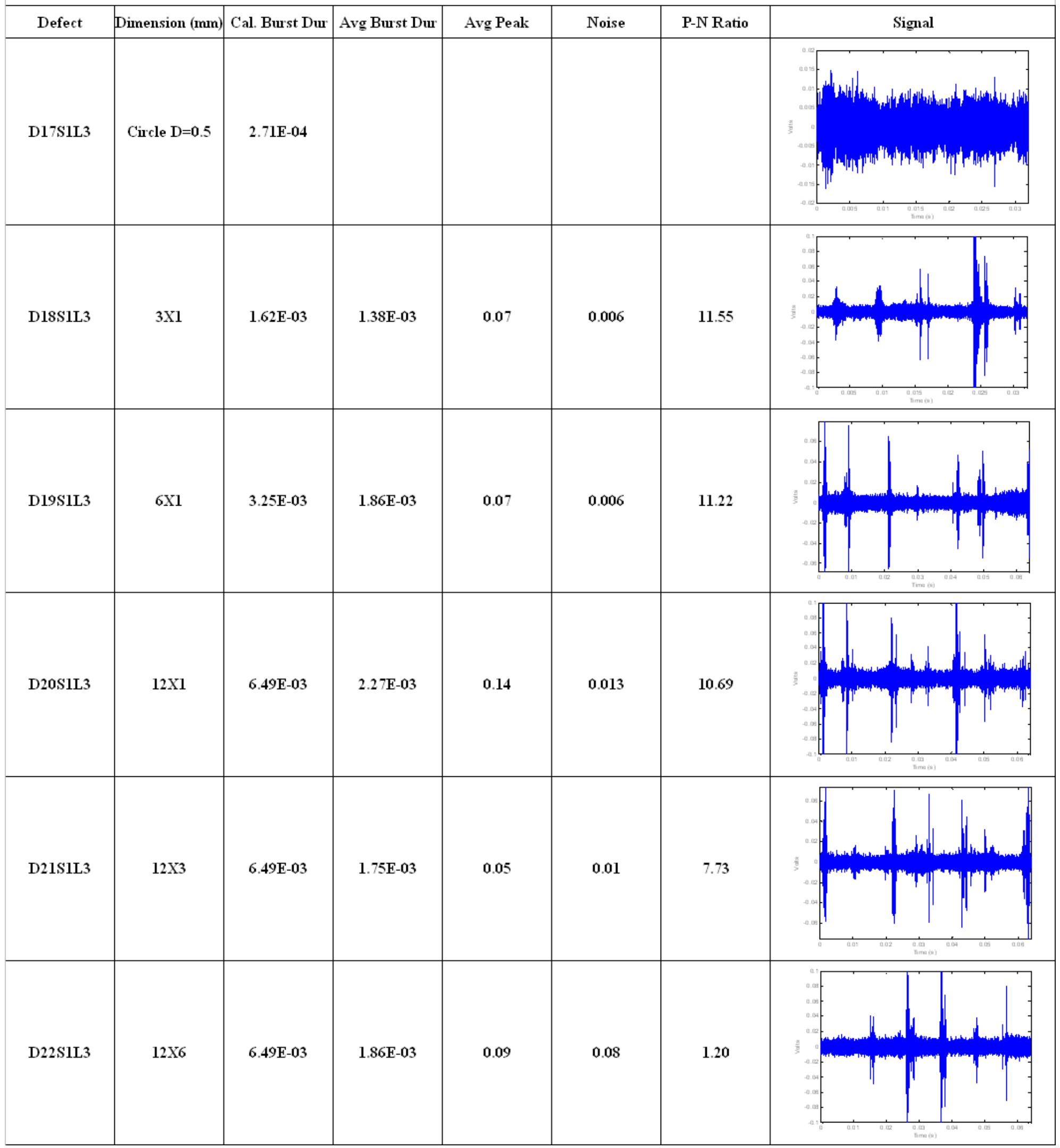


Table A10: Inner Race Defect; 30001pm Load $2.7 \mathrm{kN}$

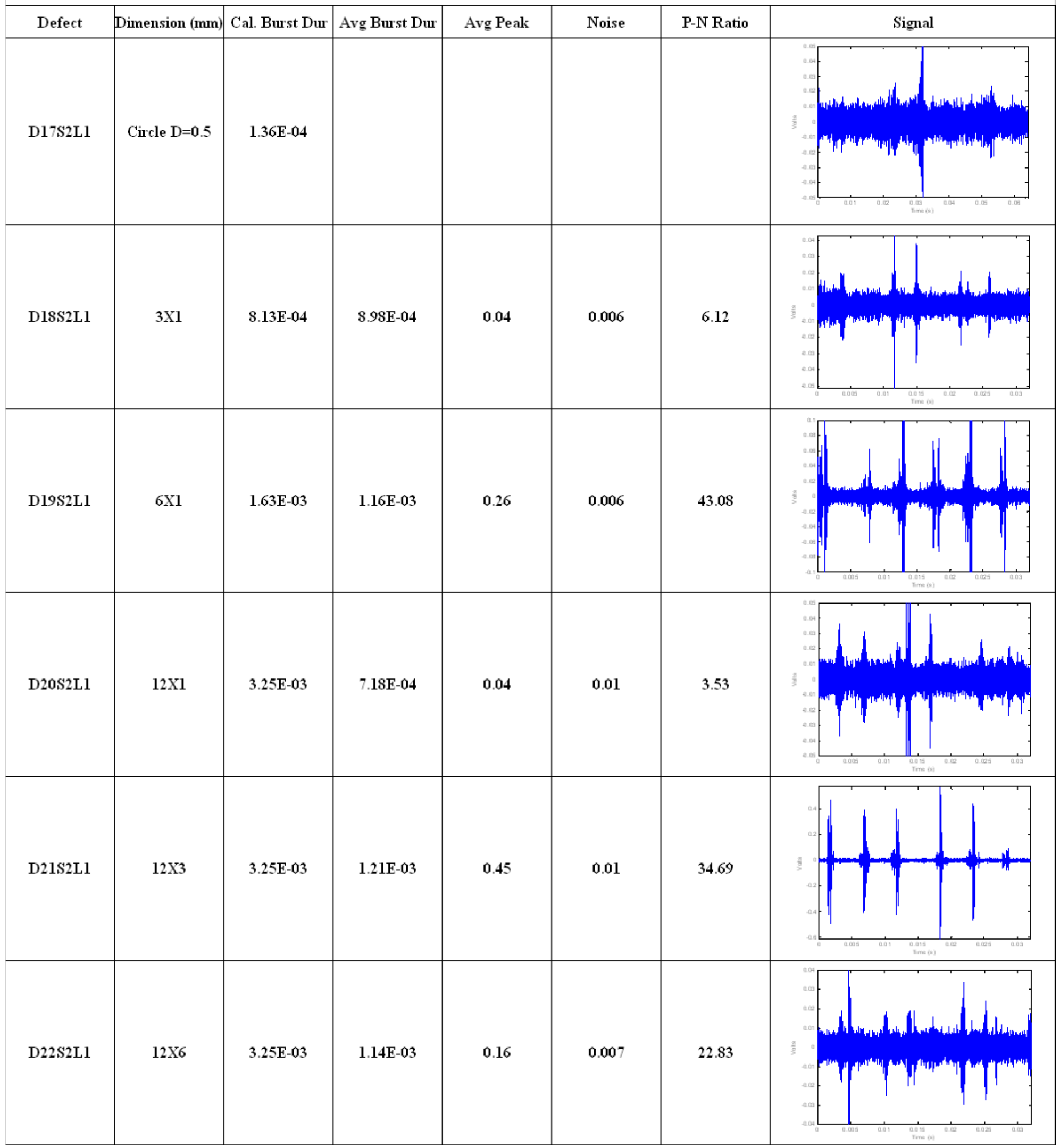


Table A11: Inner Race Defect; 3000rpm Load 5.3kN

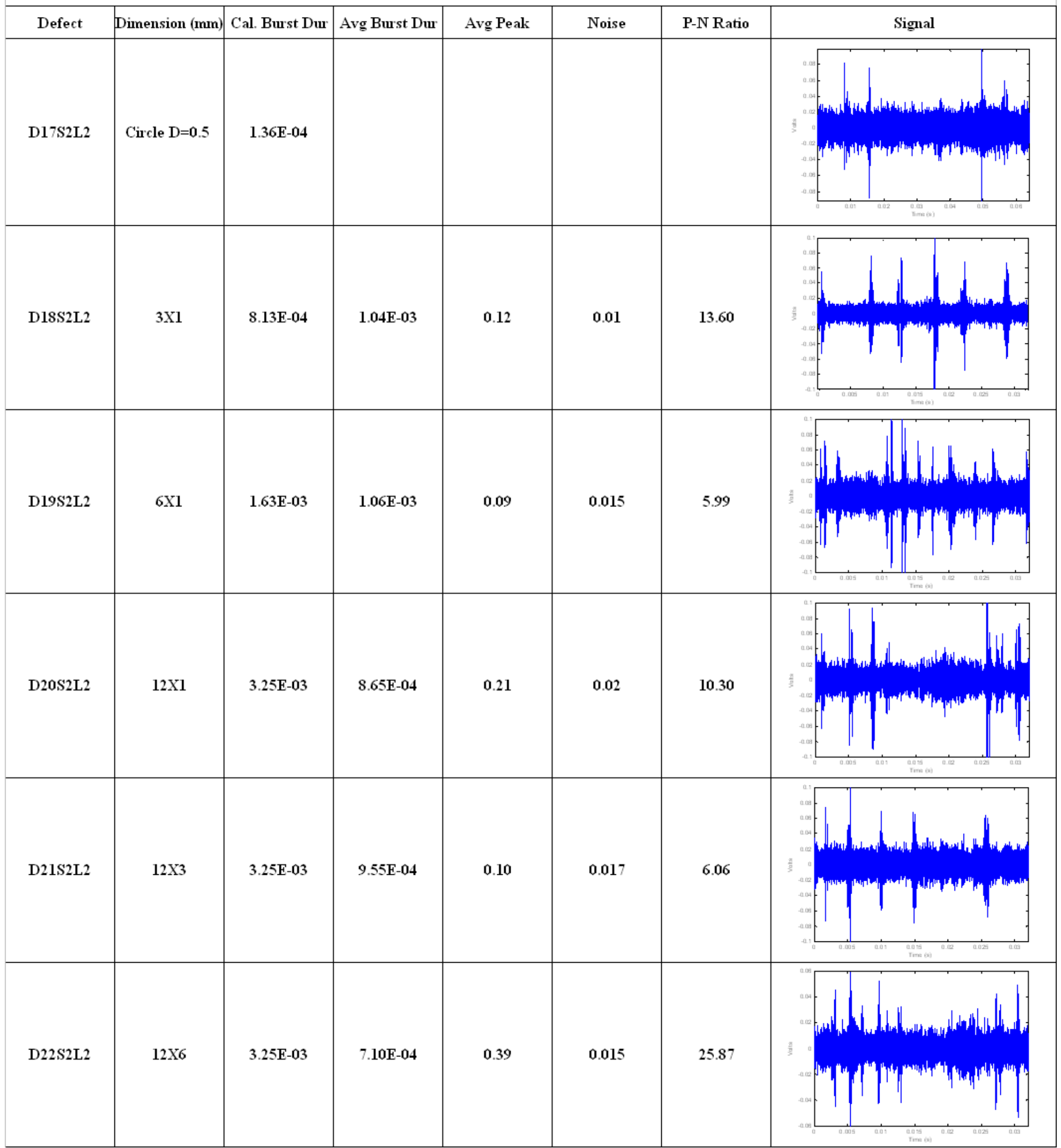


Table A12: Inner Race Defect; 3000rpm Load 8.0kN

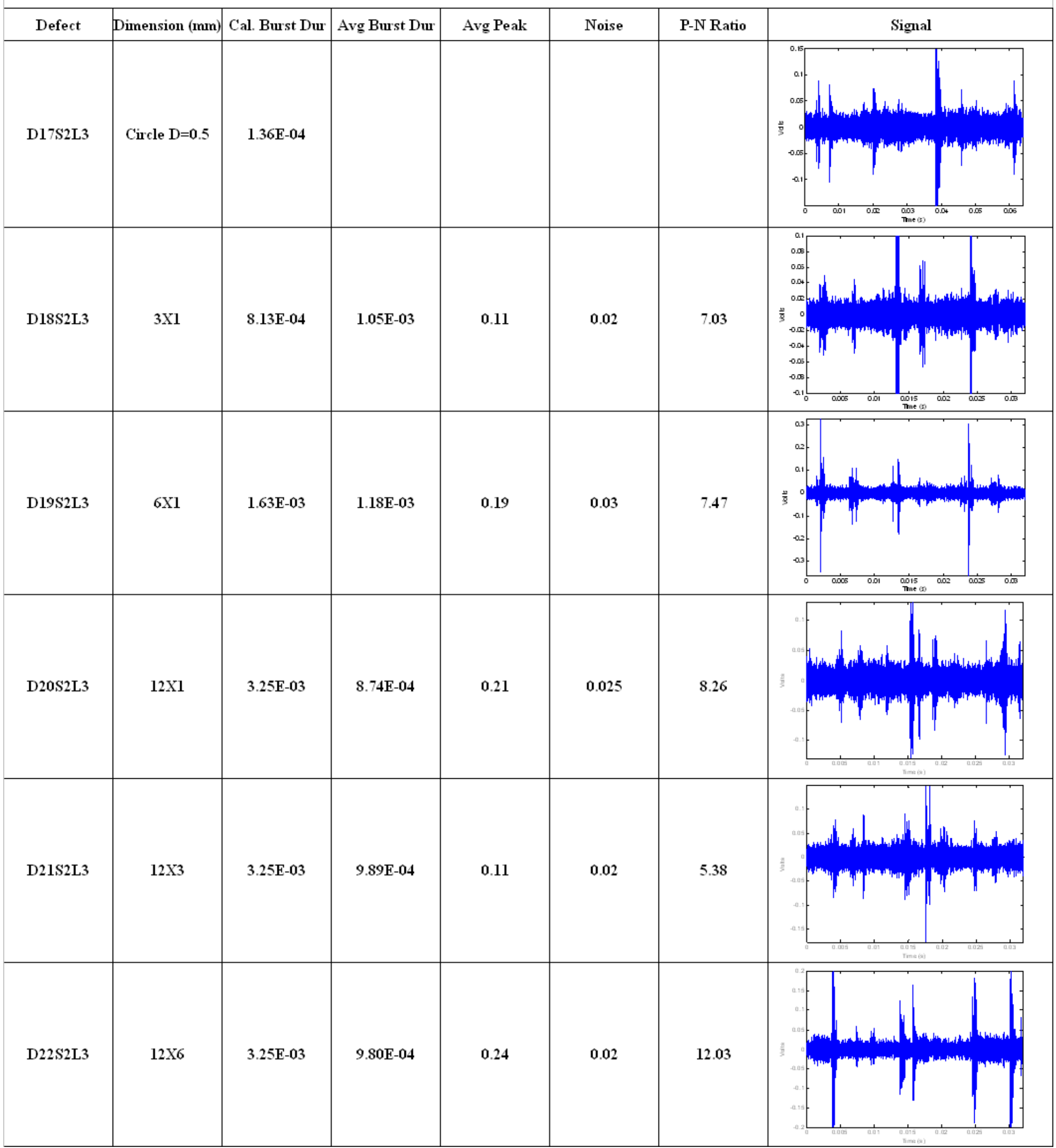

